Western University Scholarship@Western

1979

\title{
The Demand for Money in the United States Yet Again
}

David Laidler

Follow this and additional works at: https://ir.lib.uwo.ca/economicsresrpt

Part of the Economics Commons

Citation of this paper:

Laidler, David. "The Demand for Money in the United States Yet Again." Department of Economics Research Reports, 7918. London, ON: Department of Economics, University of Western Ontario (1979). 
ISSN:

ISBN :
0318-725X

$0-7714-0113-2$
$-9$

$= \pm$

,

RESEARCH REPORT 7918

THE DEMAND FOR MONEY IN THE

UNITED STATES YET AGAIN

by

David Laidler

June, 1979

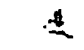




\title{
THE DEMAND FOR MONEY IN THE UNITED STATES
}

YET AGAIN

by

\author{
David Laidler \\ Department of Economics \\ University of Western Ontario \\ London, Ontario \\ N6A $5 \mathrm{C} 2$
}

I am grateful to Ted Balbach, Russell Boyer, Phillip Cagan, Keith Carlson, Michael Darby, Stanley Fischer, Joel Fried, Benjamin Friedman, Michael Hamburger; Peter Howitt, Allan Meltzer, Larry Meyer, Steve Poloz, Franco Spinelli, Jerome Stein, Cliff Stone and William $\mathrm{H}$. White for many useful comments on this paper. Since many of them disagree with aspects of my analysis, it is particularly important to exonerate them of any blame for this paper's contents.

I am also grateful to Christina Fader and Brian Bentley for excellent research assistance and to Monica Malkus for coping so skillfully with an unusually messy manuscript. 
In the 1960s, questions about the supply and demand for money and their interaction were at the very centre of research in macroeconomics. During the first stage of the monetarist debate, we were concerned with re-establishing belief in the importance of the behavior of the supply of money in influencing the level of aggregate demand. Although there is room for argument about which contributions to the resolution of the issues involved were of particular importance, there can be no doubt that the 1960s and early 1970s saw an enormous swing of opinion towards the view that, as far as aggregate demand is concerned, "money matters," and matters much more than the majority of economists (would have believed. ${ }^{1}$

However towards the end of the very period during which this swing in opinion was taking place, the centre of macroeconomic research was also shifting. Instead of continuing to worry mainly about the causes of shifts in the level of aggregate demand, we became concerned with their consequences for the behavior of output and employment on the one hand, and prices and money wages on the other. Thus, particularly in the United States, subsequent stages of the monetarist debate, rather than having anything directly to do with money, were . about the existence, stability, and micro foundations of the "expectations augmented Phillips curve." (I deliberately do not call it an aggregate supply curve because to do so seems to me to prejudge the outcome of the current debate about its micro foundations.)

Elsewhere, the supply and demand for money were not pushed quite so far from the centre of the scene. In economies more open than the United States the monetary approach to the balance of payments became a particularly controversial matter, and propositions about the nature of the demand for money function and the money supply process are obviously more central in such a context. Even 
so, the questions examined in this literature have not so much been about the details of the supply and demand for money functions per se, as about the consequences of relatively broadly drawn hypotheses about their nature for other matters.

None of this means that work on the demand for money function ceased in the 1970s, and indeed, in the last year or so there has been something of a resurgence of interest in the topic. This paper seeks to contribute to current debates in a number of ways. First, in Section II, a brief survey of recent developments in the area is presented. As we shall see, perhaps the most striking of these has been the discovery of what appears to be instability in the United States demand for money function since 1972. This matter is subsequently treated in some detail in Section III where new empirical results are presented. In Section IV, questions about the exogeneity of the money supply and what that might imply for the techniques appropriate to the estimation of the demand for money function are briefly raised. Such issues are explored further in section $\mathrm{V}$ where certain unconventional methods of estimating the demand for money function are applied to the same body of data used in section III. The results obtained with these techniques are far from . conclusive, but, as we shall see, they do at least suggest that this particular line of enquiry is worth pursuing further. Section VI sumarizes the substantive parts of the paper, concentrating in particular on the issues that they raise for further research.

\section{II}

As I have already noted, a considerable amount of work on the demand for money function has been done in the last decade. ${ }^{2}$ However, such work by and large was aimed at refining a body of theory whose broad outlines had 
already been laid down, and at consolidating empirical support for it. With certain exceptions, whose implications I shall take up in more detail below, it did not, in my judgement, produce any new insights into the nature of a monetary economy. Theoretical work extended models of the transactions demand for money to consider a margin of substitution between money and goods as well as between money and bonds (Feige and Parkin (1971), Perlman (1971)), and to make the payments period endogenous (Barro and Santomero (1974)); but such work showed that the qualitative predictions of economies of scale in money holding and interest sensitivity of demand for transactions balances, which followed from the original transactions models of Baumol (1952) and Tobin (1956) were robust in the face of such extensions; it did not produce any radically new predictions. Similarly, models based on postulating a stochastic pattern of payments and receipts for the individual agent, and hence capturing what many would regard as the essence of Keynes's "precautionary motive," were extensively analysed without apparently producing any novel and empirically sustainable predictions, at least for the aggregate demand for money function. As far as empirical work is concerned, perhaps the most striking development in the last decade has been the extent to which data on economies other. than the United States have been analysed, and the extent to which the basic hypotheses about the nature of the demand for money function, originally established utilizing United States data, have survived such extensive testing. The frequency with which a positive real income (or wealth) elasticity of demand for money, a negative opportunity cost elasticity, and a unit price level elasticity of demand for money have been found to be well determined is quite remarkable. The influence of expected inflation on money holdings has also been widely documented. Beyond these general results, it has sometimes proved possible to replicate quite closely for other countries results originally generated by 
United States data. For example, Khoury and Myhrman (1976) using Swedish data, and Spinelli (1978) using Italian data, have independently achieved essentially the same results concerning expectations and adjustment lags in the function as did Feige for the United States, in his now classic (1967) article: namely that, for long periods of annual data, adjustment lags seem to be negligible once proper account is taken of the role of adaptive expectations in determining permanent income.

The 1960s did not see every issue about the demand for money function settled, even as far as the United States economy was concerned. Broad questions about the existence and stability of the relationship, about the importance of an opportunity cost variable to its explanatory power, about the absence of a liquidity trap, and so on, did seem to be settled by the end of the decade; but that still left much scope for disagreement about other things. How best to proxy the opportunity cost of holding money, whether wealth or income was the right scale variable, whether money was better defined to include or exclude time deposits, were prominent among the questions left open and each one of them subsequently attracted attention. No test, however, seems to have generated results that have attracted anything approaching universal assent, particularly . as far as the first two questions are concerned.

Thus, those who for one reason or another are strongly attached to a transactions approach to the demand for money, for example, the proprietors of the FMP model, have continued to use a short-term nominal interest rate to measure the opportunity cost of holding money. Many monetarists, taking the view that the demand for money is the demand for a durable good, have tended to favor some measure of the rate of return on real capital both in analytic model building exercises (e.g., Brunner and Meltzer (1975)) and in empirical work (e.g., Hamburger (1977)). Moreover, Heller and Khan (1979), 
following up a suggestion of Friedman (1977) have shown that the demand for money may be sensitive, not just to one interest rate, but to the whole term structure. There has also been work on measuring the own rate of return on money. This matter was studied directly by Barro and Santomero (1972) who used survey data to construct such a measure, and also by Klein (1974), who argued that despite legal prohibitions, banks do in fact manage to pay the competitive rate of return on their deposit liabilities. Klein estimated this rate of return indirectly and showed that it displayed a significantly positive influence on the demand for money, a result confirmed by Darby (1972) and consistent with the conclusions of Barro and Santomero. Certain people working on the demand for money in open economies, for example, Hamburger and Wood (1978), have examined the possibility that interest rates ruling in international capital markets, rather than purely domestic ones, are a relevant opportunity cost variable, and have found evidence consistent with that hypothesis.

When it comes to the question of the choice of scale variable, Goldfeld (1973) reported results that seemed to him to refute Meltzer's (1963) contention that non-human wealth is the most appropriate one to use, although Benjamin Friedman (1978) has argued that wealth as well as income ought to be in the function. Furthermore, like earlier studies that used measured income as a scale variable, Goldfeld's work attributed considerable importance to adjustment lags, which following Chow (1966) were modeled econometrically by including a lagged dependent variable among the arguments of the function. Given the popularity of permanent income as a proxy for wealth (albeit a somewhat broader wealth concept than Meltzer originally used) and the practice of measuring permanent income as a function of current and lagged values of measured income, those with an a priori preference for using wealth in the function will be 
unlikely to find Goldfeld's conclusions convincing. ${ }^{3}$ Hence it is not surprising to find Darby (1972), Klein (1974) and Meyer and Neri (1975), to cite three examples, using permanent income variables--or variations thereon--in empirical work, nor is it surprising to find that the influence of wealth on the demand for money has played an important role in the purely analytical models utilized on both sides of the "crowding out" debate.

Debates about the most appropriate definition of money have almost always been between those who prefer to include only currency and demand deposits (given recent institutional developments in the United States, it might be better to say chequable deposits) in the relevant aggregate and those who wish to extend its boundaries to include time deposits (or non-chequable deposits) at commercial banks. Data exist for broader aggregates, but at least for the United States, it is hard to find anyone for whom they are a first choice to represent the concept of "money" that appears in the typical macro model. When it comes to other, more open, economies it is a different matter because, there, the use of a broader aggregate makes it easier to manipulate basic banking system balance sheet identities in applying the monetary approach to balance of payments theory. ${ }^{4}$ For the United States, even in the 1960s, supporters of M2 were in. a minority and a preference for this aggregate has never been in any sense a distinguishing characteristic of monetarists--Brunner and Meltzer, for example, have always and systematically preferred $\mathrm{Ml}$.

Work done over the last decade has tended to confirm earlier results (e.g., Laidler (1966)) that it is possible to identify separate demand functions for Ml and for time deposits (e.g., Goldfeld (1973)). It has also shown that to the extent that "expected" income is an important determinant of the demand for money, the relevant expectations are shorter term in nature as far as MI is concerned. (See Meyer and Neri (1974).) Such results as these, combined 
with the relatively low elasticities of demand for demand deposits with respect to the rate of return on time deposits that portfolio studies have always produced (Feige (1964), Feige and Pearce (1977)) and which Klein's work has only partly undermined, all serve to suggest that the assets that make up $\mathrm{Ml}$ are regarded by economic agents as providing services to some degree separate and distinct from those provided by the banking system's less liquid liabilities. 5

The work of Cagan and Schwartz (1975) also lends support to this view, although they argue that this phenomenon is one which is much more strongly apparent in post-Second World War data than in those generated earlier. This conclusion in turn suggests that the nature of the demand for narrow money function itself has tended to change systematically in response to the evolution of the financial system, and that it is only relatively recently that transactions motives have come to be of particular importance in determining its nature. If that is the case, then for purposes of analysing long runs of time series data, a broad definition of money might be expected to provide more consistent results. ${ }^{6}$ Nor is it in any way ruled out as being a usable aggregate for analysing more recent experience. However, the consensus conclusion now seems to be that important details are more likely to be uncovered if the distinction between demand and time deposits is recognized.

The picture that emerges from the preceding brief discussion is one of steady if unspectacular progress, of a gradual refinement of our understanding of the properites of the demand for money function, and of a considerable broadening of the empirical basis of that understanding. The progress in question has had its effect on policy. The United States is far from being the only country where, in the 1970s, far more attention has been paid to the behavior of the money supply than in the past, not merely by commentators on 
policy but also by policymakers themselves. Unfortunately, this increased attention to the behavior of the money supply has coincided with the onset of apparent instability in the demand for money relationship, not just for the United States, but for other countries as well--for example, Britain and Australia. ${ }^{7}$ Anyone who remembers the late 1960 s when a well determined unemployment-inflation trade-off vanished as soon as policy attempted to exploit it must find this extremely disturbing, not least because such commentators as Kaldor (1970) warned that instability in the demand for money function would materialize the moment attempts were made to control the behavior of the money supply. Hence, it is worth looking at this apparent instability in some detail, and that is what I shall do in the next section of this paper, concentrating on recent United States experience.

\section{III}

It is important to be clear from the outset that the instability which has attracted so much attention is in a particular version of the demand for money function, namely that embodied in the FMP econometric model. This function is based on a "transactions" approach to the demand for money. It deals with the demand for Ml balances and permits economies of scale to be present in the relationship. The scale variable in the function is measured income, rather than permanent income or wealth, and the opportunity cost of holding money is measured by a short interest rate. The only marginally unconventional thing about this function is that, in treating velocity rather than money balances as the dependent variable, and including a lagged dependent variable on the right-hand side, it constrains the adjustment lags in the relationship to be the same with respect to income, interest rates, and prices. There can be no question but that, down to 1972, the function fits very well 
indeed, and that thereafter it goes wrong. The key question is whether this relationship was misspecified in the first place, or whether its breakdown is symptomatic of a structural change that has occurred in the economy.

In a recent paper, Hamburger (1978) has addressed this issue, and has concluded that the problem stems mainly from the specification of the function. In particular, he shows that the out-of-sample forecasting ability of a function. that includes as arguments both a long interest rate and a return on equity variable, and which constrains the real income elasticity of demand for money to be unity, is much better than that of the FMP model equation, although its in-sample-fit down to 1972 is somewhat inferior. Without in any way wishing to denigrate Hamburger's valuable work, I believe the problem warrants further attention, not least because, in constraining the real income elasticity of demand for money to be unity, Hamburger's formulation is bound to cause skepticism among advocates of a transactions approach to the demand for money. Moreover, I can think of no good a priori reason why lags in the demand for money function should be constrained to give the same speed of response of cash balances to all arguments, and there is no way, short of relaxing this restrictive assumption, of knowing how important this factor might be in influencing the poor forecasting. performance of the FMP equation.

Accordingly, using quarterly data for the period 1951 (1) - 1978(1), kindly provided by Hamburger, I set about investigating these issues further. Rather than treat velocity as the dependent variable I used money balances and, with a regression package that permitted the imposition of non-linear overidentifying restrictions on parameter estimates, attempted to estimate a log. linear demand for money function in which the dependent variable was permitted to respond at different speeds to each argument in the function. Convergence problems rendered this effort fruitless. The next step taken was to impose instantaneous 
(within one quarter) adjustment of the demand for nominal balances to prices by using real balances as the dependent variable and dropping the price level from the right-hand side of the equation, but convergence problems were still encountered. Thus two even more simplified versions of the function were tested, one in which real balances adjust at the same speed to variations in income and interest rates--a conventional adjustment lag formulation of the demand for real balances function--and one in which the response to interest rate variations is instantaneous--a conventional error-learning-permanent-income formulation. Both forms impose a different lag pattern on the function to that implied by the FMP equation. I also experimented with an adjustment lag formulation of the relationship in which lagged nominal balances were deflated by current rather than lagged prices. Such a relationship, implying as it does a lagged response of the demand for money to price level changes of the same speed as to variations in other arguments, is much closer to the FMP function. However this formulation systematically produced a slightly negative adjustment parameter and I do not, therefore, present the results here.

Initially a single opportunity cost variable was used with a short nominal rate $\left(r_{1}\right)$, a long nominal rate $\left(r_{2}\right)$ and a real rate $\left(r_{3}\right)$ being entered successively. 8 In each case the regression was fitted to data for $1953(1)$ $1972(4)$, and $1953(1)-1978(1)$. The parameter estimates from the shorter period were used to predict money holdings for the period $1973(1)-1978(1)$, and the results of doing so are summarized in the statistics referred to as $e$, the mean prediction error arising from this exercise, and $n$, the number (out of 21) of overpredictions of money holdings (underpredictions of velocity). Since the logarithm of real income appears on the right of the equation and hence is assumed to be known, and since the dependent variable is a logarithm, e may be 
interpreted as the proportional error in predicting the velocity. Note that the out of sample prediction exercise carried out here differs from those reported by Goldfeld (1977) and Hamburger (1978) in that the actual rather than the predicted value of the lagged dependent variable was used to generate each forecast observation. With the techniques used here a once and for all shift of the function at a particular date causes subsequent prediction errors to be roughly uniform in sign and size; with the Goldfeld-Hamburger technique they become cumulatively larger in such circumstances. There seems to be no reason to prefer one approach to the other for current purposes, provided that the results are interpreted appropriately. ${ }^{9}$

With all variables in logarithms and the symbols having conventional meanings, Table 1 contains results generated by the following model:

$$
\begin{aligned}
& (m-p) *=\alpha+\beta y+\gamma r \\
& (m-p)-(m-p)_{-1}=\theta\left[(m-p) *-(m-p)_{-1}\right]+u \\
& u=\rho u_{-1}+\mu
\end{aligned}
$$

The alternative permanent income model performed systematically worse on any criterion than the adjustment lag form. Also, because the non-linear constraints on the values of the structural parameters that it implies required the use of an iterative estimation routine, the Cochrane-Orcutt technique for dealing with first-order autocorrelation in the residuals, used in generating the results presented in Table 1, could not readily be applied to it with available software. For these reasons, and to save space, the results generated by this alternative model are not presented.

A number of characteristics of the results set out in Table 1 are worth noting. First, the function's outside sample predictions are biased except in the presence of $r_{3}$ alone, but this equation's other characteristics disqualify it from serious consideration. However, it would be surprising if an equation 
containing a real interest rate variable alone did perform well by itself here, given the inflation experienced towards the end of the sample period. Second, the size of the prediction errors, as measured by $e$, is greatest for the equation that most nearly resembles the FMP demand for money function, equation (1). Third, the adjustment speeds implied by the coefficients of the lagged dependent variable, though positive, would be judged by many to be implausibly low. Fourth, the value of $\rho$ changes markedly when post-1972 observations are added to the sample, suggesting that some structural change occurred at about that date. Finally, Table 1 contains evidence to suggest that the demand for $M I$ balances is characterized by returns to scale, so that results generated by Hamburger's modification of the FMP function, to impose a unit income elasticity upon it, are open to suspicion on that score, a suspicion however that turns out to be groundless, as we shall now see.

An important element in Hamburger's work is the inclusion of two interest rates, one real and one nominal, in the function. Table 2 contains the results of using interest rates in pairs. Results for the "error-learning-permanentincome" formulation of the function were again calculated but are not presented here to save space. Suffice it to say that all the problems with this formulation that were apparent when only one interest rate was included in the function were also encountered, indeed were enhanced, when an extra interest rate variable was added to it. Also, a form with lagged nominal balances deflated by current prices was fitted and again systematically yielded a coefficient in excess of unity for that variable. The results reported in Table 2 largely speak for themselves. It is possible to include two interest rates in the function, but more satisfactory results arise when the combination used is of a real and a nominal rate, either short or long, rather than of two nominal rates. On balance, there is nothing to choose between Hamburger's preferred 
combination of a long nominal rate and a real rate and a short nominal rate and a real rate. Moreover, when such pairs of interest rates are included, the estimate of the real income elasticity of demand for money rises considerably, suggesting that Hamburger's function was not, after all, badly misspecified by constraining the real income elasticity of demand for money to unity. Finally it should be noted that the results presented in Table 2 confirm Hamburger's conclusion that the inclusion of a real interest rate variable, through it reduces problems with the demand for money function for the post-1973 period, does not completely eliminate them. The mean prediction error is always below 18 , but the function nevertheless underpredicts velocity 16 or 18 times out of 21 .

Two further possible sources of problems with the stability of the function were looked at, and their results are worth some discussion. The level of interest rates has been, on average, substantially higher since 1972 than before. A log. linear form constrains the interest elasticity of demand for money to be constant. With a semi-log form, for which there are many precedents in the literature on the demand for money, the interest elasticity of demand rises with the level of the interest rate. 10 It seemed worth asking whether the systematic underprediction of velocity after 1972 stemed from the extrapolation of a constant interest elasticity function into a period of generally higher rates, where the extrapolation of a semi-log relationship would have been more appropriate. Thus, all the relationships presented in Tables 1 and 2 were recomputed using the natural value rather than the $\log$ of the interest rate as an independent variable (or variables). The results are not reported in detail to save space but are easily summarized. The predictions of such relationships after 1972 do show less bias than that of those discussed above, but on every other count--goodness of fit, statistical significance of 
particular parameters, stability of parameter estimates when data for after 1972 are added--they are inferior. The apparent instability of the demand for money function is difficult to explain by a simple specification error of this kind although it should be noted that Khan (1979), using the whole term structure rather than a single interest rate, reports more promising results from an otherwise similar exercise.

The second possible source of the problem that I considered merits more detailed discussion, because though its investigation emphatically did not lead to any improved estimate of the demand for money function for recent years, it did produce results that cast doubt on the robustness of conclusions recently reported by Benjamin Klein. In (1977) Klein showed that a variable measuring the short-term unpredictability of the price level seemed to have a significant positive effect on the demand for money in the United States, the underlying theoretical rationale being that, when unpredictability of prices reduces the services provided by a given quantity of real balances, economic agents compensate by holding more of them. Although Klein showed that the variable in question was statistically significant in pre-World War II data considered alone, its influence on the velocity of Ml was particularly marked in a sample . of data for the 1953-72 period. Subsequently, in the light of comments by Ibrahim and Williams (1978) on related work, Klein (1978) published a revised annual series, that extends to 1976, for the short-term unpredictability of prices. It seemed worth asking whether variations in the "quality" of money could have had anything to do with the recent behavior of velocity, and to use Klein's published data as a basis for the investigation. As we shall see, the outcome of this line of investigation is to cast doubt on the robustness of Klein's earlier results. Some relevant estimates are presented in Table 3. The data used above 
were converted to annual average form to generate them. In the results reported $\pi$ represents the parameter of klein's variable. As the reader will see, for the 1953-72 period this parameter takes a positive sign in all three equations reported, but it gets close to conventional levels of statistical significance only when a long interest rate is included in the function. This is consistent with the results that Klein himself set out in (1977) because a long interest rate was the only opportunity cost variable included in his 1953-72 velocity function. When the years 1973-76 are considered, either in terms of the predictive power of an equation including Klein's variable, or by simply adding them to the sample, the results are startling. The equation's predictive power outside the sample is appalling, and the addition of four extra years of data is enough to change the sign that Klein's variable takes well beyond the bounds of conventional levels of statistical significance in the case of the very relationship for which it was most nearly significantly positive for the 1953-72 period. Equations using pairs of interest rate variables were also estimated and produced results qualitatively similar to those presented here. However, the positive sign on Klein's variable before 1973, and the negative sign thereafter, were both less well determined in this case. Clearly the foregoing results make it impossible to attribute any apparent instability in the demand for money function to variations in the quality of money, at least as measured by Klein's variable. However, these results also have a broader significance. It would be well worth someone's while to see how much the apparent deterioration of this variable's performance in the regressions reported here relative to its performance in Klein's study is due to the addition of a few extra years of data, how much is due to the revisions which klein himself has made to its measurement since using it in his (1977) paper, how much is due to the rather simpler form used for the 
demand for money function here, and, most important of all, how significant these factors are for the robustness of the general conclusions that Klein drew about the role of the influence of the "quality" of money in the demand for it. 11

So far I have confined my discussion to tests that use Ml as the dependent variable of the demand for money function. Ten years ago, after an extensive discussion of the issues involved in choosing an appropriate specification for the money stock, I concluded that as far as matters such as goodness of fit and stability of the demand for money function are concerned, there was nothing to choose between Ml and M2. (See Laidler (1969).) Some tests appeared to favor one concept and others another, without any result being sufficiently clearcut to convince any uncommitted spectator. It is only in the last few years that a narrow definition of money has become the commonly accepted one, and that is, I suspect, as much because the Fed has chosen to state policy targets for a narrow aggregate, and because that is the definition favored by the proprietors of the FMP model, as because new and particularly convincing evidence in favor of this definition has turned up (though, as I have noted above there has been some of the latter). Hence it seemed worth asking whether . the problems I am here discussing are solely the property of functions that seek to explain the demand for $\mathrm{Ml}$. Accordingly, all the tests reported above for Ml were duplicated with M2 as the dependent variable, and a sample of results is reported, en bloc, in Table 4.

As with Ml, a simple adjustment lag formulation of the function does perform marginally better than an error-learning-permanent-income formulation and hence those results are reported. Nevertheless, it should be noted that there is much less to choose between the two formulations when M2 is used, and in fact, the out-of-sample forecasting performance of the permanent income 
formulation is slightly better. Also as with $\mathrm{Ml}$, the use of a short interest rate as an opportunity cost variable gives the best fit up to 1972 combined with the worst outside sample forecasting performance. However, the deterioration of the function after 1972 is less marked, and is all but wiped out by the simple substitution, or addition of, a long interest rate to the relationship. Moreover, though the inclusion of a real interest rate variable does produce sensible results, it seems much less crucial to include this variable in the relationship than it was when Ml was the dependent variable. As to the Klein variable, results not reported in detail confirm that its qualitiative performance is similar when M2 is used, as far as sign is concerned, but that the variable never achieves statistical significance at any conventional level, with either a positive or negative sign. Finally, it should be noted that results also not reported in detail confirm that the use of a semi-logarithmic form for the demand-for-money-interest-rate relationship produces a deterioration in the function's goodness of fit as the price for an improvement in its post-1972 forecasting ability, just as it did when MI was used. However, the changes in performance are less notable.

It is apparent from Table 4 that, more often than not, M2 relationships. display a small residual sum square and a lower outside sample prediction error than those utilizing $M I$, indicating that the velocity of this broader definition of money is slightly easier to explain and predict with functions of the type used here. Moreover, estimates of the income elasticity of demand for money seem much less sensitive to the other variables in the function. They are also, as I have noted, much less influenced by a switch to a permanent income formulation of the function. In part of course all this is due to the fact that M2 is a more inclusive aggregate than $M I$. A given percentage error in predicting the latter, other things equal, necessarily implies a smaller percentage error 
in predicting the former. However, the improvement in post-1972 forecasts achieved by broadening the definition of money seems to be too great to be accounted for solely in these terms. If the results reported so far are taken at face value, some of the unexplained shift out of Ml after 1972 seems to have been into time deposits. I shall return to the implications of this observation in section vI below.

IV

I have already noted above that the United States has not been the only country where suspicions about the stability of the demand for money function have recently been raised. The same thing has happened in Australia and Britain, and has produced a direct response from Lewis (1978) and Artis and Lewis (1976). They argue that modeling lags in the demand for money function along the conventional lines followed so far in this paper involves a specification error, and that the apparent instability of the function results from this specification error. They base their case on an insight that also underlies work of Jonson e.g, (1976b), Carr and Darby (1978), Knight and Wymer (1979), Laidler and O'Shea (1979) but which seems to originate with Walters (1965), and may be put as follows.

The conventional approach to estimating the demand for money function involves first specifying a "long run" relationship, that typically makes the demand for money depend upon a scale variable and an opportunity cost variable, and then postulating, along Marshallian lines, that the "short run" demand for money adjusts gradually over time in response to changes in the arguments of the long-run function. Though it may be reasonable to treat the behavior of the individual agent in this way, it does not follow that it is also reasonable to model the economy as a whole "as if" it were such a single agent. If the nominal supply of money is used as the dependent variable of the demand function, 
it is only in economies in which the supply of money responds passively to variations in the demand for it that this practice can lead to a correct specification of the short-run behavior of the money market. In other cases, the dynamics of the money market must involve adjustment of the arguments of the demand for money function to changes in the money supply, rather than vice versa, and such a process is not properly captured in conventional formulations of those dynamics. If real balances are used as the dependent variable, then if nominal balances are exogenous, the lag pattern of a conventionally specified function is at best capturing the adjustment of one argument in the demand function, namely the price level, to changes in other variables, and not any simple portfolio adjustment.

Artis and Lewis (1976) dealing with British data suggest that misspeciflcation of adjustment dynamics did little harm to estimates of the function based on the relatively tranquil 50 s and 60 s, but like Jonson (1976b) argue that, when confronted with data for the much more volatile 70 s, it is crucial to model those dynamics appropriately. Whether or not this argument should be taken seriously as far as United States data are concerned clearly depends upon whether, in that economy, the arguments of the demand for money function adjust to changes in . the money supply, or vice versa. ${ }^{12}$ That is a question as much about the processes whereby the money supply is determined as about the demand for money function. The adjectives "endogenous" and "exogenous" are slippery, not least when they are applied to the money supply. Let us be clear, then, that we are dealing here with the nominal rather than the real money supply, and also that, under almost any conceivable set of institutional arrangements, short of pure helicopter money, the nominal money supply has its long-run equilibrium value determined simultaneously with the values of the variables that normally enter the demand for money function. The issue of endogeneity and exogeneity 
arises here in the context of a specific problem, namely how to obtain estimates of the parameters of the long-run equilibrium demand for money function from observations taken when the economy, rather than being on that function, is in the process of moving towards it. Hence it concerns such matters as the nature of the shocks that lead to the economy being moved away from long-run monetary equilibrium, and the variables that subsequently adjust to restore it. In principle, anything could be a source of disturbance, and everything will adjust in response; however our question concerns what in practice are the most frequent sources of disturbance and which variables usually bear the brunt of subsequent adjustments.

If we were dealing with an individual agent instead of the economy as a whole, the answers here would be uncontroversial. Certainly the general price level and the level and structure of interest rates are given to such an agent, and though his income and wealth are obviously susceptible to manipulation by him, particularly in the long run, there probably would be little objection to treating them as being given also, at least as a first approximation. On the other hand, the individual's holdings of cash balances are obviously under his own control. Given his income, their average value will vary with his expenditure patterns, and he has ready access to asset markets as well. Only to the extent that his cash income is subject to unforeseen transitory shocks, might his money holdings vary as a consequence of anything other than his own choices. In short, it makes eminently good sense to model the individual as adjusting his cash balances to changes in the arguments of the demand function while the influence of transitory income on his money holdings can be dealt with along lines analysed by Laidler (1966) and Darby (1972). 13

For the economy as a whole, matters are less straightforward. Though the relationship between the monetary base and the money supply does vary as 
a result of the portfolio decisions of the banking system and the non-bank public, over all but very short periods such variations are relatively minor. Hence, if the behavior of the base is determined independently of the wishes of the private sector vis-à-vis its money holding, then that sector, when it is off its long-run demand for money function, cannot be modeled "as if" it were merely a representative individual agent. To do so, as I noted in Laidler (1977), is to commit a fallacy of composition. However, I believe that many would argue that in the United States the actual conduct of policy in recent years has in fact been such as to make it appropriate to think of the money supply and the base as responding to demand side factors, and hence to model the short-run dynamics of the demand for money function in the conventional way utilized so far in this paper. They would defend that view in the following way. Whatever changes there may or may not have been in the targets and indicators of monetary policy since, shall we say, 1953, its instruments have consistently been interest rates. The monetary authority has attempted to achieve whatever may have been its ends by standing ready to buy and sell government securities at a given price (although not necessarily a pegged price). If over any reasonably short period--say a quarter-real income and prices may be regarded as predetermined, and if the monetary authority, and hence the banking system, stands ready to buy and sell securities at a given price, then there is no obstacle in the way of the economy as a whole adjusting its money holdings towards a desired level at a pace of its own choosing. Given this view of the money supply process, the conventional stock adjustment approach to estimating the demand for money function is correctly specified for the United States, whatever may be the drawbacks to the use of such a specification for other times and places.

The argument just presented rests upon a version of what Brunner and 
Meltzer have termed the "money market hypothesis" of the generation of the money supply, adapted to a situation in which the interest rate rather than the monetary base is the policy instrument. That hypothesis, though widely accepted, is nevertheless controversial. The alternative "credit market" hypothesis differs from it in insisting that the non-bank public's supply of securities to the banking system is not simply the mirror image of its demand for the liabilities of that system. Rather, Brunner and Meltzer note that the non-bank public also holds income earning assets of a type distinct from those that it supplies to the banks. It is most convenient to think of this third asset as reproducable physical capital. To get to grips with the significance of the credit market hypothesis for the questions I am raising here it is helpful to begin with a situation of full portfolio equilibrium on the part of the banking system and the non-bank public, and then ask what happens when the monetary authorities raise the price at which they are willing to buy securities.

The "money market" hypothesis tells us that the public will want to hold more cash balances, and will attempt to acquire them by offering securities to the banking system which will in turn acquire the base necessary to supply that money by offering securities to the authorities. Any influence on output and prices will come later as a consequence of the effect of the lower interest rate on the level of aggregate demand for goods and services. As output and price level changes materialize, more money will be forthcoming from the banking system as the public demands it. In short the stock of money will passively adjust to changes in the arguments of the demand function.

The "credit market" hypothesis leads one to tell a very different story. Certainly the rise in security prices will lead to an attempt to increase money holdings, but it will also lead to an attempt to substitute physical 
capital for securities. If the whole of the non-bank public is trying to make such a substitution, the trick can only be accomplished by selling securities to the bank and taking the proceeds to buy physical capital--but of course the proceeds of such a sale of securities are going to take the form of money, newly created not because the non-bank public as a whole wants to hold it, but because each individual member of that public wants to use it to offer in exchange for capital. Once created, however, that money must be held, but its creation will precede the setting in motion of streams of expenditure that in turn will have consequences for the other arguments of the demand for money function, namely output and prices. Eventually, the economy will end up with new levels of income, prices, money holdings and so on, that may differ little from those which would be predicted by a model that ignored the distinction between securities and physical capital. However, the process whereby it approaches this equilibrium is critically different, in that it involves excess money operating upon expenditure flows in order to force the arguments of the demand for money function to move towards new values, rather than having money creation responding passively to changes in those arguments. 15 The foregoing arguments fail to touch on yet another reason for treating . the money supply as exogenous to the behavior of the arguments of the demand for money function, even when the monetary authorities are treating the interest rate as their principal policy instrument, namely that it is not only the extension of credit to the private sector, but also to the fiscal authorities that leads to the creation of money. Even if, at a particular rate of interest, the values of income, prices, the rate of return on capital and so on are such as to render the supply of money and bank credit compatible with portfolio equilibrium on the part of the banking system and the non-bank public, that in no way guarantees either that the fiscal authorities' budget is in balance, or 
that, if it is not, the private sector will be willing to absorb just the right number of new government bonds to finance whatever deficit is being incurred. A fiscal deficit can therefore become an independent source of monetary expansion when the monetary authorities are treating the interest rate rather than the base as their policy instrument, even in an economy with well developed capital markets such as the United States. Once again money creation will cause variations in the arguments of the demand for money function rather than vice versa.

\section{V}

The arguments just presented make an $\underline{a}$ priori case for believing that, particularly over time periods in which the economy is "off" its long-run demand for money function, causation might run primarily from the behavior of the supply of money to the arguments of that function rather than vice versa. If that is the case, then it follows that the conventional dynamics embodied in short-run demand for money relationships are misspecified. As I have already noted, this possibility was raised as long ago as 1965 by Walters, but it has only been in the last two or three years that people working in the area, notably Artis and Lewis (1976), Jonson (1976a), Carr and Darby (1978), have begun to follow up its implications for estimating the demand for money function.

Although each one of them would probably agree that, in principle, exogenous shocks to the money supply lead to adjustments in all the arguments of the demand for money function, and in the case of an open economy in the balance of payments and/or the exchange rate as well, of those just named it is only Jonson who has taken this proposition as the basis for his empirical work. 16 A complete model of the economy is required to implement such an approach 
empirically, and there is no need to dwell on the onerousness of the research task that this implies. Hence it is understandable that others have been content to adopt simpler, special case, hypotheses that require only single equation methods. However, theoretical differences may also underlie the fact that various workers have usually chosen to focus on different particular variables as bearing the main impact of the shocks that push the economy "off" its long-run demand for money function. Specifically, Artis and Lewis have envisaged interest rates as bearing the major burden, Carr and Darby have concentrated on the price level, while Jonson, although his empirical work has dealt with complete models in which all variables adjust, has nevertheless highlighted expenditure, and hence income, in his theoretical writing on the closed economy case. In the next few pages, I shall take up each approach in turn and present the results of tests using the same data that underlie the results contained in Section II above. The results in question are, however, at best preliminary because, throughout, single equation techniques are used even though the arguments of the preceding section of this paper point to the ultimate desirability of modeling and estimating the properties of both the demand and supply functions for money simultaneously within the context of . a complete model.

Let us proceed to consider the results in question, beginning with the approach that Artis and Lewis have successfully applied to British data. Although they do not say so explicitly, a Keynesian view that has the interest rate proximately determined by the supply and demand for money underlies their work..$^{17}$ As I do in this paper, they use quarterly data, and argue that over such a time interval real income and the price level may be regarded as predetermined. In the face of an exogenous change in the money supply, that leaves only the interest rate free to adjust towards a value that will make the economy, in the 
long run, willing to hold all the cash in circulation. Specifically, a log. linear form of their model may be written as follows, where $r$ is the long-run equilibrium value of the rate of interest.

$$
\begin{aligned}
& (m-p)=\alpha+\beta Y^{p}+\gamma r^{*} \\
& y^{p}-y_{-1}^{p}=\lambda\left(y-y_{-1}^{p}\right) \\
& r-r_{-1}=\mu\left(r^{*}-r_{-1}\right)+w
\end{aligned}
$$

The results of estimating this model using both $M 1$ and $M 2$ are presented in Table 5, but it might be noted that a simpler form of this relationship, using current real income as the scale variable, was also estimated with qualitatively similar results which therefore are not reported here. Because of the software limitations referred to above, no attempt was made to adjust for the presence of serial correlation in the residuals of the reduced form of this model. 18 Table $5 a$ refers to a narrow definition of money and $5 b$ to a broader one and speak for themselves. Whatever success may have been gained by using the hypothesis under test here to deal with British data, it does not work for Ml in the United States. No matter what rate of interest is used, the parameters of relationships involving Ml are never well-determined for the 1953-72 . period, although they occasionally appear to take a priori reasonable magnitudes. The results are much better with M2, but a glance back at Table 4 will confirm that the results obtained for M2 by conventional methods look no worse. It is difficult to resist the conclusion that the relatively reasonable parameter estimates obtained here for the demand for M2 function tell us as much about the robustness of that relationship as about the short-run dynamics of the money market.

As we shall now see, M2 also fares much better than Ml in tests based on the postulate that real income bears the brunt of the economy's initial 
adjustment towards re-establishing long-run equilibrium in the money market. The rationale for this approach is that, given the values of whatever other arguments might appear in the function determining real aggregate demand for goods and services, the latter will be higher the greater is the discrepancy between the quantity of money the economy must hold, and the quantity of money that it would willingly hold in the long run at prevailing values of the arguments of the relevant demand for money function. It postulates the existence of what Jonson has called a "disequilibrium real balance effect." Implicit in this approach is the assumption that prices are sufficiently sticky that changes in expenditure flows lead initially to changes in output rather than simply being absorbed by price level changes. It is thus the product of an eclectic approach to macroeconomics in which classical cash balance mechanics interact with Keynesian price stickiness.

It will be apparent that if the problem of estimating the long-run demand for money function is to be tackled along such lines, hypotheses must be formulated not only about the form of that function, but also about the determinants of aggregate demand and the response of output to aggregate demand. This readily explains why the proponents of this approach have undertaken the . construction of complete macroeconomic models; it also implies that the results that I have obtained with it, and present below, can at best be regarded as exploratory. These results have been generated using single equation techniques, and stem from rather elementary formulations of the aggregate demand function, not to mention the primitive assumption that aggregate supply responds at once to meet aggregate demand.

Thus, where $\mathrm{E}$ is aggregate real expenditure, $\mathrm{Y}$ is real income, $\mathrm{Y}^{\mathrm{P}}$ is permanent income and $\mathrm{z}$ is a "catch all" vector of other variables, an income determination system of the following general type is postulated. 


$$
Y=E=K\left(\frac{s_{-1}}{M_{d}}, z_{-1}\right) Y_{-1}^{p}
$$

A stochastic log. linear special case of this system, with lower case letters standing for logarithms, and $y^{p}$ and $y^{t}$ being the permanent and transitory components of the log of income is

$$
y=y^{t}+y^{p}=k+\alpha_{1}\left(m_{s-1}-m_{d_{-1}}\right)+\xi z_{-1}+y_{-1}^{p}+n
$$

This may be supplemented by the following demand for money function

$$
m_{d}=\alpha+B y^{p}+\gamma r+p
$$

to yield, as a reduced-form expression determining $y^{t}$

$$
y^{t}=\alpha_{0}+\alpha_{1}\left(m_{s}-\beta y_{-1}^{p}-\gamma r_{-1}-p_{-1}\right)+\xi_{-1}+\eta
$$

Here $\alpha_{0}$ contains all constants, included the permanent income growth rate $\left(y^{p}-y_{-1}^{p}\right)$. Also, the error term, which may be thought of as containing a stochastic element from the demand for money function, is postulated to take the form

$$
n=\rho n_{-1}+\varepsilon
$$

It will be noted that the demand for money function (9) postulated here is perfectly conventional, but that the expression $\left(m_{s}-m_{d}\right)$ in equation (8) represents an alternative hypothesis about short-run adjustment dynamics to the conventional one embodied in equation (2) on p. 11 above. As I have already noted, this hypothesis states that, if the arguments of the demand for money function do not take a set of values which make the private sector of the economy just willing to hold the quantity of money in circulation, the result will be a flow of expenditure and output that is positively related to the excess supply of money. In short it states that money which is "unanticipated," in the sense that prices, permanent income, and interest rates have not adjusted to its existence, 
influences expendiure and output. Though this hypothesis is clearly related to that embodied in Barro's recent work $(1977,1978)$, it is not the same, because the latter rests upon a very special view of how expectations about the time path of the money supply are formed and about how these expectations in turn come to influence the price level, a view which is in no way an integral part of the hypothesis under study here. I will return to this issue below.

In principle a wide variety of variables could be included in the vector $z$, but in fact the roles of only two such variables were explored, namely transitory income, and the interest rate. The latter was used for obvious reasons, and the former because, although the permanent income hypothesis tells us that consumption is independent of that variable, it also tells us that expenditure, including as it does outlays on durable goods, may not be. Two alternative ways of measuring permanent income were used. First, a conventional error-learning model was tried, and second, the variable was proxied by the time trend value of real income. ${ }^{20}$ The interest rate in the demand for money function was represented successively by a short and a long nominal rate, and in some experiments the parameter $\gamma$ was set equal to zero. Given that in Section III of this paper two interest rate variables were often included simultaneously in the long- . run demand for money function, the procedure used here needs further explanation. Consider the possibility that interest rates do influence the demand for money in the usual negative fashion but also exert a direct negative influence on aggregate demand: their overall effect on aggregate demand in an expenditure equation such as (10) will be ambiguous. An increase in interest rates will tend to reduce aggregate demand by way of its direct influence on that variable, and tend to increase it by way of reducing the demand for money. The only way to identify these two influences separately using single equation techniques is to use two interest rate variables, one 
assigned to the demand for money function, and one assigned to the expenditure function itself. It is natural to assign a nominal interest rate to the demand for money function and a real rate to a direct role in the aggregate demand relationship. In such a case we have two interest rates on the righthand side of the expenditure equation to be estimated in any event, and to add a third introduces an unacceptable degree of multicollinearity into the relationship.

Furthermore, note that transitory income is positively correlated with the level of interest rates, and exerts, if anything, a positive influence on expenditure. Its presence in the expenditure equation therefore also creates difficulty in obtaining a well-determined relationship between the demand for money and the interest rate by the means being adopted here. None of these problems is ultimately insurmountable. In a complete macro model, "unanticipated" money would appear in other equations too, and appropriate estimation techniques would in principle enable the information contained in all of them simultaneously to be used to pin down the demand for money function. ${ }^{21}$ However they present genuine difficulties when single equation techniques are being used, and the above discussion adds further weight to the warning I have already given about the exploratory nature of the results under discussion here.

Table 6 contains the results generated for M2 when the trend value of real income was used as a permanent income proxy. Their salient characteristics are easily summarized. First of all, it does turn out to be possible to get reasonable parameter estimates for the demand for money function which are relatively insensitive to the precise formulation of the expenditure equation. Second, the real rate of interest turns out to exert a robust and well-determined negative influence on real expenditure and income. This result is important for two related reasons: it makes it difficult to interpret the results 
presented here as simply reflecting the same forces captured by the conventional methods used in Part III of this paper, and it suggests that the role of the real rate of interest as it relates both to the demand for money and the level of expenditure is complex and would be worth investigation with more sophisticated econometric techniques than those used here. Third, the role of the nominal rate of interest in the demand for money function is not systematically well established by these results. The expenditure equation seems to have room either for the nominal interest rate in the demand for money function, or for lagged transitory income as a determinant of current expenditure, but not for both. The probable reasons for this, having to do with multicollinearity, have already been discussed, and once again the implication seems to be that the matter should be studied further with more powerful econometric techniques than those used here.

Finally, and most important, the notion that transitory fluctuations in income may be interpreted as resulting from expenditure flows set in motion by a discrepancy between the supply of money, and the long-run demand for money is sustained by the results presented in Table 6 . Moreover, as the reader will see, the parameter relating the transitory component of the log. of income to "unanticipated" money, though well-determined, is relatively small. Darby (1972) and Carr and Darby (1978), using more conventional techniques to estimate demand for money functions, find the demand for money to be highly sensitive to the transitory component of the log. of income, indeed more sensitive than to its permanent component; Barro (1978) also finds it necessary to invoke a similar highly sensitive relationship in order to reconcile the parameter estimates that result from his attempts to explain output fluctuations as a response to his estimates of unanticipated changes in the money supply with those arising from his attempts to explain 
the behavior of prices in a fashion consistent with his market-clearingrational-expectations model. The results reported here suggest that a rather insensitive causal relationship running from money to transitory income might be being misinterpreted by these workers as a highly sensitive relationship running in the other direction. Again, the matter is clearly worth further investigation. 22

The results presented in Table 6 are encouraging, and it would be pleasant indeed to be able to report that when a more elaborate error-learning proxy for permanent income was used, they stand up strongly. Unfortunately they do not. To proxy permanent income in this way imposes non-linear constraints across the parameters of the expenditure equation with which we are dealing, and convergence problems plagued attempts to get well-determined parameter estimates of this formulation of the model. Where convergence was achieved, the relevant parameter estimates were reasonably consistent with those already discussed, and indeed suggest that to proxy permanent income by a trend is not a bad approximation, but it was not achieved in enough cases to enable such a judgement to be made with any confidence at all.

It would also be pleasant to report that the results contained in Table 6 are insensitive to the definition of money employed, but again they are not. Table 7 displays a sample of results achieved with Ml, the "best" ones, be it said. Once again the influence of lagged transitory income and the real interest rate on expenditure are well-determined, as is usually the parameter relating expenditure to the lagged level of the real money supply. However it is only occasionally that sensible parameter estimates for the demand for money function itself can be found. One is forced to the conclusion that even if conventional models do misspecify the short-run dynamics of the market for Ml, the unconventional one under consideration here is even more misspecified. 
The hypothesis underlying the results just discussed is that, if the arguments of the long-run demand for money function are not such as to make the public willing to hold the quantity of money in circulation, then extra expenditure flows will be set in motion. Money that is in this sense "anticipated" by the arguments of the demand for money function will be held, and that which isn't will be spent, causing changes in output. The phrase "anticipated money" has had much play in the macroeconomic literature recently, but as I have already noted the meaning there attached to it has been rather more specialized than that just accorded it. In the work of Barro $(1977,1978)$ and Carr and Darby (1978), it refers to those changes in the quantity of money that have been both forecast by the private sector, and to which the general price level has then been adjusted. Though these authors agree with one another on what happens to money thus anticipated--it is willingly absorbed into cash balances--the relationship between their views on what happens as a consequence of unanticipated changes in the money stock is unclear. For Barro such changes cause output fluctuations and I have already pointed out that the results presented in Table 6 are somewhat in the spirit of his work, although inconsistent with the specific formulation of his rational-expectations-market-clearing model.. On the other hand, Carr and Darby argue that unanticipated changes in the money stock are initially added to cash balances, result first in a deviation of actual cash holdings from their long-run desired level, and then lead, by a mechanism that they do not specify, to a slow adjustment of the price level and hence of real balances towards a long-run equilibrium value.

According to Carr and Darby, the conventional stock adjustment formulation of the demand for money function is misspecified to the extent that it ignores the shocks to actual holdings of real balances that result from unanticipated changes in the money supply. For them, the exogeneity of the money supply implies 
that an extra variable, measuring unanticipated changes in the money supply, should be added to the right-hand side of the short-run demand for money function. Because they regard the adjustment that underlies their model as price level adjustment, rather than portfolio adjustment, they argue explicitly that lagged real balances, and not lagged nominal balances deflated by current prices, should be on the right-hand side of their equation. Although Carr and Darby note that their notion of "anticipated money" is formally the same as Barro's, they model it as the outcome of an autoregressive process determining the behavior of the money supply, rather than attempting, as does Barro, a structural explanation of that variable's behavior. They add the deviation of the actual money stock from such a series to the right-hand side of a quarterly demand for money function for the United States and show that this variable adds considerable explanatory power to that relationship, at least down to 1972 .

A number of comments on this procedure are in order. First, the actual nominal money stock is, of course, a component of the dependent variable of their equation, and any measurement errors in it will also be present in their unanticipated money series. Second, the conventional demand for money equation explains real money holding as a function of prices, income, interest rates, and lagged real money. All of these four variables are highly autocorrelated, so that, even setting aside questions of measurement error, it is not too surprising to find that the fluctuations in money holdings that such an equation cannot explain are related to deviations from an autoregressive model fitted to money itself. In short, there must be some suspicion that Carr and Darby have come close to adding the error term itself as a regressor to the right-hand side of their equation. 23

The above remarks, of course, concern their econometric technique, not 
the potential economic validity of their hypothesis. However that hypothesis is open to the comment that it is peculiar to postulate that prices adjust instantaneously to changes in the money stock which are expected to happen, but adjust only slowly to those which have already taken place; and to the criticism that the transmission mechanism underlying the latter adjustment is left unspecified. Nevertheless, it is surely worthwhile to experiment with the Carr-Darby hypothesis further, particularly to see if unanticipated changes in the money supply could be responsible for the post-1972 behavior of velocity.

It did not seem altogether appropriate to use Carr and Darby's unanticipated money series for further work, because the formula by which they generated it was derived explicitly in the context of a study of the demand for money; had it not fitted there, it would presumably not have been published; and in any event they publish their series only down to 1972. However, Barro too has published such a series (1978), conceptually similar to that of Carr and Darby, but developed in the context of a study of fluctuations in income and employment. It was therefore decided to test the explanatory power of Carr and Darby's hypothesis about the demand for money function using Barrọ's data. Barro's series is an annual one, and measures the deviation of the actual money stock from a year ahead forecast of that variable, unlike Carr and Darby's series which is underpinned by a quarter ahead forecast. Barro therefore attributes much more volatility to the unanticipated component of the money stock than do Carr and Darby, but his series nevertheless performs rather well in the demand for money function, as a glance at Table 8 will confirm. The results reported there, based of course on annual data, are for $M I$ only, because Barro's series is for unanticipated $\mathrm{Ml}$, and are easily summarized. Even with two interest rates in the demand function, including a real rate, 
the post sample forecast error for the conventional demand for money function is considerably larger than that which arises with quarterly data, but the addition of the Barro variable to the function--its coefficient is called $\phi--$ significantly improves the relationship's performance. It takes a significantly positive sign in all cases, and its coefficient does not vary when the sample period is extended beyond 1972 except when the real interest rate is missing from the equation. The post-1972 forecasting ability of the demand for money function is also considerably enhanced by the presence of the variable. Moreover, note that the relatively slow adjustment implicit in the coefficient of the lagged dependent variable presents no problem in the context of the Carr-Darby hypothesis. A sluggish portfolio adjustment might be implausible, but not a sluggish price level adjustment.

These results cannot be conclusive. Residual doubts must remain about how much more has been done here than explicitly to add a good proxy for the error term to the right-hand side of the demand for money function, and this is not to mention questions about the transmission mechanism that causes prices to respond to unanticipated money. Nevertheless they are highly suggestive. In particular, they show that of the three approaches to coping with exogeneity of . the money supply which we have considered in this section of the paper, that of Carr and Darby is the only one that enables us to generate any sensible estimates of the parameters of a demand function for narrow money. They also show that this approach can contribute to the explanation of the apparent instability of that demand function after 1972. If the results presented in Table 8 are taken seriously, they suggest that the sudden monetary contraction that began then was unanticipated, and itself was responsible for a good deal of the subsequent unexplained rise in velocity.

Now none of the hypotheses tested here have generated definitive results, 
and indeed it is not clear that those results are either entirely consistent with one another, with those presented in Section III, or with the analysis of Section IV. The next, and concluding, section of this paper will be devoted to discussing the issues involved here and to drawing some tentative conclusions about what we have and have not learned about the demand for money function from the work set out in this paper.

VI

The results that have been presented in this paper are by no means satisfactory in every respect. Many of the issues taken up require further work if there is to be any chance of resolving them. I will touch briefly on the possible nature of such work in a moment. However, a number of conclusions about the nature of the demand for money function can be drawn from the results in question and it is to these that I turn first of all.

Perhaps the most striking characteristic of the empirical work described above is the relative robustness of the demand for money function when a broad definition of money was employed. When dealing with what I have termed "orthodox" approaches to modeling the short-run dynamics of the money market it turned out to be easier to forecast M2 out of sample than MI; the parameter estimates of the long-run function seemed less sensitive to the precise choice of variables to be included; those parameters changed less with a change of time period; and as results not reported in detail showed, the parameters were much less prone to fluctuate when permanent income lags were substituted for adjustment lags in the conventional framework. Moreover, when less orthodox approaches to modeling the dynamics of the money market were employed, the contrast between M2 and Ml results was even more dramatic. The former variable still produced parameter estimates both for the long-run parameters of the function, and for the adjustment parameters of whatever dynamic adjustment was 
postulated, that could be regarded as sensible a priori. The latter, except in the case of the Carr-Darby hypothesis, generated nonsense results.

One should not conclude from all this that there does not exist a stable long-run demand function for narrow money, because given the "right" choice of opportunity cost variables and the "right" dynamic specification of short-run behavior it is certainly possible to come very close to producing one. Nevertheless it is much easier to defend the choice of M2 than Ml, because to do so does not require that a particular set of arguments for the long-run function and a particular specification of short-run adjustment dynamics also be defended. Thus, the work described in this paper certainly suggests that M2 is a more appropriate choice of monetary aggregate both for empirical analysis and perhaps policymaking as well. ${ }^{24}$ This conclusion might seem to need defending in the fact of a great deal of evidence (e.g., Feige (1964), Laidler (1966), Goldfeld (1973), Cagan and Schwartz (1975), Meyer and Neri (1975)), which indicates that time deposits are a distinct entity, the demand for which should be modeled separately. However I do not believe that this evidence is in fact inconsistent with the conclusions I have just drawn.

The key here lies in an argument put forward originally by .Alvin Marty (1961) and taken up by Cagan and Schwartz, to the effect that, as the financial system has become more developed, Ml has become a more and more specialized aggregate which increasingly satisfies transactions motives for money holding; over time, more and more agents have found that asset motives, initially also satisfied by $M I$, could be satisfied by time deposits, and indeed by other liquid liabilities of both banks and non-bank intermediaries. If that is the case, then the battery of motives fulfilled by holding M2 may have remained more consistent over time than those underlying the demand for any particular specification of $\mathrm{Ml}$. If that were the case, then in time series analysis such 
as we have been carrying out here, the demand function for M2 would indeed turn out to be more stable.

This conclusion by no means precludes the possibility that, over short periods, when little innovation is going on in the financial sector, a better approach to modeling the demand for M2 would be to follow Laidler (1966) and Goldfeld (1973), and to treat the demand for Ml and time deposits separately. Moreover if the factors causing shifts in the Ml function could be identified in advance and incorporated in the specification of the function to be fitted, then once again, the advantages of going straight to an aggregate demand for M2 function would be lost. However, if the pace at which the technology of the financial system is changing is erratic and difficult to forecast--and even in those tests with Ml that were relatively successful it was never possible completely to get away from the conclusion that the function has shifted since 1972--then as a practical matter it may be better to stick with a broader definition of money. After all, monetary policy is implemented over time, and unless the relationship which it seeks to exploit can be relied upon to remain stable over time it cannot be used successfully. Even if, as I suspect it might, the "missing money" of the post-1972 years turns out to have gone into newly . invented assets that are to all intents and purposes perfect substitutes for demand deposits, so that in some sense the "true" demand for narrow money turns out not to have shifted at all, this will not help matters. ${ }^{25}$ such a development needs to be forecast ex ante and not merely identified ex post if it is not to undermine the conduct of policy.

However, it needs stressing that the demand function shift in question is less dramatic than one might have inferred from earlier work. The apparently cumulative shift of the function portrayed by Goldfeld (1977) and Hamburger (1978) stems from their use of a dynamic out of sample forecast. The static 
forecasts used here show that what occurred was more akin to a once and for all shift of the relationship than to a cumulative collapse. Moreover my work has confirmed Hamburger's conclusion that the particular form of the relationship used in the FMP model may well have been misspecified in the first place. A skeptic, however, would note that the real interest rate variable, that makes such a notable contribution to maintaining the function's performance after 1972 seems to have been of more marginal importance in the relationship before then. It is also worth noting that some of the problems involved here stem not from the specification of the demand for money function itself but rather from that of short-run adjustment dynamics. As a comparison of Table 1 with Table 8 will confirm, when adjustment is specified on a quarterly basis, the function forecasts beyond 1972 with considerably more accuracy than it does when an otherwise similar function is specified in annual terms.

Now it was precisely in order to get to closer grips with the question of how to specify alternative short-run money market dynamics that I briefly analysed the money supply process in Section IV of this paper and then went on to carry out the tests whose results were presented in Section $v$. The first thing to be said about those results in the current context is that, whatever else they do, they do not rescue the demand for Ml function from the suspicion of instability. Even the application of the Carr and Darby analysis to annual data still leaves some systematic forecast errors, although it does improve things a great deal. However, I would argue that the often unsatisfactory results presented in section $V$ indicate that further work is required rather than that the line of enquiry that they represent should be abandoned. The arguments which underpin that line of enquiry amount to saying: first that the nature of the money supply process in the United States is such that causation runs primarily from money to the arguments of the demand 
for money function rather than vice versa, with the effects in question being spread out over time; and second that this implies that conventional short-run demand for money adjustment lag dynamics are misspecified. I went on to try out three very simple alternative specifications of such dynamics, involving in turn the propositions that the burden of adjustment falls upon interest rates, expenditure, and prices. With MI, except in the last case, these tests produced poor results, but with M2 their outcome was much more promising: certainly promising enough to support the conclusion that such hypotheses are worth pursuring further.

First of all, some further and quite straightforward empirical work on the Carr-Darby hypothesis would be worthwhile. We already know that that hypothesis works well for quarterly data on Ml down to the end of 1972, and have shown here that it also gets support from a longer series of annual data for the same aggregate. The next step surely would be to extend that hypothesis' application to a broader money concept. Given the robustness displayed by M2 relationships in this study, and given that there does not seem to be much of a problem with the underlying long-run demand for money function when that aggregate is used, it would be surprising if the Carr-Darby model did not hold . up well in the face of such extra testing. Such work would certainly add to our factual knowledge about the behavior of the demand for money function in recent United States history, but it would not contribute directly to the solution of what I believe is the major puzzle raised by the work presented in Section $v$. That requires further theoretical work before empirical evidence can be brought to bear on it."

I have argued, albeit briefly, in section IV of this paper that, when it comes to modeling short-run dynamics, causation should be thought of as running predominantly from the nominal money supply to the arguments of the 
demand for money function rather than vice versa, and also that this observation implies that the usual interpretation of the presence of a lagged dependent variable in "short run" demand for money functions as reflecting the presence of portfolio adjustment costs cannot be sustained. The presence of such a variable needs an alternative explanation, and the one usually offered, namely that it reflects slow adjustment of income expectations, is not supported by the evidence I have presented, at least as the whole explanation. Something else also seems to be going on in the data I have analysed, and Carr and Darby (following Walters) suggest that the lagged real balances variable is picking up sluggish adjustment of one of the arguments in the demand for money function, the price level, to changes in the nominal money supply. That in turn means that what is being estimated is not a Marshallian short-run demand for money function but some peculiar mixture of a long-run demand for money function and some sort of reduced-form equation for the price level. Quite what sort of a mixture this might be cannot be said until the details of the transmission mechanism running from money to prices are specified.

One possible mechanism would involve changes in the nominal money supply, or rather "unanticipated" changes in that variable, influencing prịces by way of a chain of causation involving interest rates, aggregate demand and output; but this line of reasoning suggests that some form of the Artis-Lewis model, and of the expenditure equation which I have associated with Jonson's work, are not so much alternatives to the Carr-Darby model as complements to it. Although this conjecture raises an ultimately empirical question, it is obvious that its logic needs to be carefully explored in the context of a complete macro model before relevant empirical tests can be formulated properly. Closely related to this issue is one concerning the relationship between Barro's work on the influence of "unanticipated" money on output and employment and the results 
reported above. I have already pointed to certain similarities between.the spirit of Barro's work and that which underlies much of section $v$, but also to some crucially different details. Thus, Barro has a very definite hypothesis about what it is that predetermines the price level--it is expectations about the value of the money supply--and he also requires the economy always to be "on" its demand for money function. Neither of these hypotheses is present in the work of Jonson, and indeed the second one is very explicitly denied by him. To discriminate between these bodies of work by way of empirical tests once more requires first of all that the logical properties of fully specified macroeconomic models need to be analysed.

To sum up then, the single equation techniques used in this paper have provided results that do more to clear the way for further work than to settle issues in and of themselves. I have argued that questions about the short-run dynamics of the supply and demand for money are fundamentally questions about what is usually termed the "transmission mechanism" and hence require a complete system rather than a single equation approach to investigate them further. In particular, models of the type developed by Bergstrom and Wymer (1974), Jonson (1976a), Jonson, Moses and Wymer (1976), Knight and Wymer (1979), etc., are well worth modifying for application to United States data. Since such models are not underpinned by rational expectations, and are based on the premise that markets clear only slowly, the significance of developing them goes far beyond the matter of getting better estimates of money market dynamics. They provide an approach to macro-modeling that is an alternative to that implicit in the rational-expectations-market-clearing tradition and hence open up the possibility of some badly needed comparative testing of the implications of that tradition. 
FOOTNOTES

${ }^{1}$ As evidence of this proposition one need do no more than cite Franco Modigliani's Presidential Address to the American Economic Association, Modigliani (1977).

${ }^{2}$ I have only recently surveyed much of this material in Laidler (1977). The treatment of recent developments in empirical work is much more detailed there than the treatment of theoretical work. For recent developments in monetary theory per se, Barro and Fischer (1976) provides an extremely useful source of information.

${ }^{3}$ Moreover, the already cited paper by Feige (1967) was precisely designed to distinguish between these two interpretations of the presence of a lagged dependent variable in the demand for money function and came down firmly on the side of the permanent income interpretation, as of course does the more recent work of Spinelli (1978) and Khoury and Myhrman (1976).

${ }^{4}$ See, for example, the work of Jonson (1976a) and Laidler and O'Shea (1978) on the UK, where a broad definition of money is used for just this reason.

${ }^{5}$ For a critique of Klein's work see Carlson and Frew (1978).

${ }^{6}$ I will return to this set of issues in much more detail below, see particularly pp. 38-39.

7For the United States, see Entzler, Johnson and Paulus (1976), Goldfeld (1976). For the UK see Hacche (1974) and Artis and Lewis (1976). For Australia see Lewis (1978).

${ }^{8}$ The interpretation of the dividend price ratio, to which I here refer as a "real" rate of interest, is controversial and complex, and as we shall 
see this variable plays a key role in the work that follows. The issues involved here are too complex to be dealt with in a footnote and are taken up in Appendix B.

${ }^{9}$ I am indebted to Michael Hamburger for straightening out my own earlier confusion about these matters.

${ }^{10}$ See, for example, Cagan (1956). Note however that Frenkel (1977), who actually tests for the appropriate specification of the demand for moneyinterest rate relationship using some of Cagan's hyperinflation data, finds little to choose between the log. linear and Cagan's semi-log forms.

${ }^{11}$ I am indebted to Benjamin klein for some useful correspondence concerning these results and their interpretation.

12 Note that it is the demand function for broadly defined money rather than narrowly defined money that gives problems in the British case.

${ }^{13}$ Both papers argue that transitory income is initially accumulated in the form of cash balances, and produce evidence to show that this effect can be supported by postwar United States data. However, though it may be reasonable to suppose that the individual agent might accumulate some of his transitory income in the form of cash balances, there seems to be a real problem with this hypothesis at the aggregate level, a problem that was not fully appreciated either by Laidler or Darby: can it be the case that transitory fluctuations in income in the aggregate occur independently of the behavior of the money supply? If they do not, how can a single equation technique that uses the money supply as a dependent variable correctly identify the influence of transitory income on the aggregate demand for money?

${ }^{14}$ Brunner and Meltzer have given many accounts of their model of the money supply process over the years, and of its implications for macroeconomic 
modeling. Among the most relevant articles are Meltzer (1958), Brunner and Meltzer (1964), (1972), (1975).

${ }^{15}$ The above argument is abridged and impressionistic. The analysis underlying it is set out in more detail by Howitt and Laidler (1979) where it is applied to problems generated by the Bank of Canada's recent attempts to achieve money supply targets by way of interest rate manipulation. For a thorough statement of the case that conventional modeling of lags in the money market is appropriate, see White (1978).

${ }^{16}$ Jonson has built models of the UK (see Jonson (1976a)) and of Australia (see Jonson, Moses and Wymer (1976), and Norton (1978)).

${ }^{17}$ To treat the interest rate as the adjusting variable here does seem to be at odds with the argument of the preceding section that the interest rate itself is the instrument of monetary policy. This may well account for the poor performance of the Artis-Lewis model in the face of United States data particularly when a short interest rate was used. Nevertheless, given the success that they report in accounting for apparent instability in the UK demand for money function with such a model it seemed worthwhile to attempt to apply it to United States data.

${ }^{18}$ Durbin-Watson statistics are biased in the presence of a lagged dependent variable and hence are not given in Table 5. Although those generated by our program were in the region $1.5-2.0$, even a cursory inspection of the residuals of the regressions reported there suggests that serial correlation problems are probably greater than these statistics might indicate. Hence the results set out in Table 5 ought to be treated with caution.

19 Note that a disequilibrium real balance effect in no way hinges upon the assumption that money is net wealth. See Jonson (1976b). For an alternative 
account of the basic mechanisms involved here see Laidler (1975, Ch. 1).

${ }^{20}$ Laidler and O'Shea (1978) and Spinelli (1979) use this variable to proxy permanent income in their models of the UK and Italy.

${ }^{21}$ Although what is possible in principle often turns out to be difficult indeed in practice. In $(1976 \mathrm{~b})$, Jonson found it necessary to constrain the real income elasticity of demand for money to be equal to unity before he could obtain sensible results for the rest of his model. The income elasticity of demand for money is also one of the less robust parameters in the RBA 76 model.

22 The residual sum squares figures presented in Table 6 are for the log. of real income. Given that we assume that we "know" the money supply, they may be regarded as errors in explaining velocity and are in that sense comparable with the residual sum squares data given in Table 4. It is therefore not irrelevant that the residual sum squares of Table 6 are often smaller than those presented in Tables 1, 2, and 4, or that the out of sample prediction biases, whose signs have been adjusted to make them comparable with those presented in earlier tables, seem less important.

Also, a number of the expenditure equations set out in Table 6 were also fitted to annual data and often produced smaller residuals over the period 1955-76 than did Barro's (1978) more elaborate equation. of course this comparison is merely suggestive, because we are here dealing with only a subset of the years to which Barro fitted his model, while the coefficients of our model, though remaining quantitatively the same when applied to annual data (except that of lagged transitory income), tended to lose statistical significance.

${ }^{23}$ In fairness to Carr and Darby it should be noted that they also include transitory income as an argument in their demand for money function. However 
I find it hard to accept their justification for doing so. They argue that their formulation follows from a model in which the demand for money depends upon wealth and in which transitory income is accumulated as cash balances. 'There seems to be an element of double-counting in this formulation. It is worth noting that Carr and Darby find that a log. linear approximation to Darby's " (1972) function, which is not open to this criticism, is not robust. 24 The relative robustness of $M 2$ demand functions in the United States is also noted by Boughton (1979) in a paper that became available only after this one was virtually completed. 
APPENDIX A

Data

Real Income: GNP in constant 1972 dollars

MI : Data are averages of last month of the quarter and first month of next quarter and are centered at the end of the quarter.

M2: As for MI.

$\mathrm{Rl}$ : Rate of return on 3-month government securities, end of quarter.

R2: Yield on long-term US bonds, end of quarter.

R3: Dividend price ratio on common stock, end of quarter.

P: GNP deflator

Annual data are averages of the above except SEE which is Klein's measure of short-run price unpredictability taken from Klein (1978), Table 1, column headed SE, and DMR which is Barro's measure of unanticipated money growth taken from Barro (1978), Table 1, column 3. 


\section{APPENDIX B}

Throughout this paper, I refer to the divident price ratio as a "real" rate of interest. Apparently there is some doubt about whether it measures such a rate rather than a nominal rate of return on a real asset. My reason for preferring the former interpretation is easily stated. The asset whose price forms the denominator of the rate of return in question is a real asset; variations in the purchasing power of money, ceteris paribus, are reflected in changes in its nominal value. Such variations are not reflected in dividend payments. The latter represent a current income stream--measured in current dollars to be sure--but include no compensation for changes in the purchasing power of money. If they did, such changes would cease to influence the price of stock and the latter would become a nominal rather than real asset. Thus dividends represent a yield, measured in units of current purchasing power, on stock, whose value is also measured in units of current purchasing power, before any adjustment for inflation; that is, a real rate of return. Changes in stock prices are reflected nowhere in the dividend price ratio, and hence it cannot be regarded as a nominal rate of return. Readers of this paper who do not find this chain of reasoning convincing are warned that they will have to reinterpret my results in a number of places to make them consistent with their beliefs.

It should also be noted that Benjamin Friedman (1978) has pointed out that the major fluctuations in the dividend price ratio since 1972 have come, not in the stream of dividends, but in the value of stock. Hence he suggests that that variable, rather than measuring the opportunity cost of holding money on a relevant margin, in fact is acting as a proxy for wealth, a constraint variable, in the function. This argument is not entirely semantic, for Friedman shows that the demand for narrow money function does in fact perform a little 
better when a wealth variable replaces the divident price ratio. The uncommitted observer of the debate about the stability of the demand for money function will presumably conclude that the demand for narrow money did undergo a once and for all fall shortly after 1972 and that, statistically speaking, the event can be "explained" by a variable that also took a step change at about the same time. The durability of any such "explanation" of post-1972 events obviously requires testing against data which do not stem from those years. In this respect the relatively poor performance of the dividend price ratio prior to 1972, particularly when it stands by itself in the demand for money function, is disturbing, though I hasten to add that this is hardly conclusive evidence against its importance thereafter. I am content to leave further arguments about this matter to those who are more committed, either for or against this variable, than am I. 


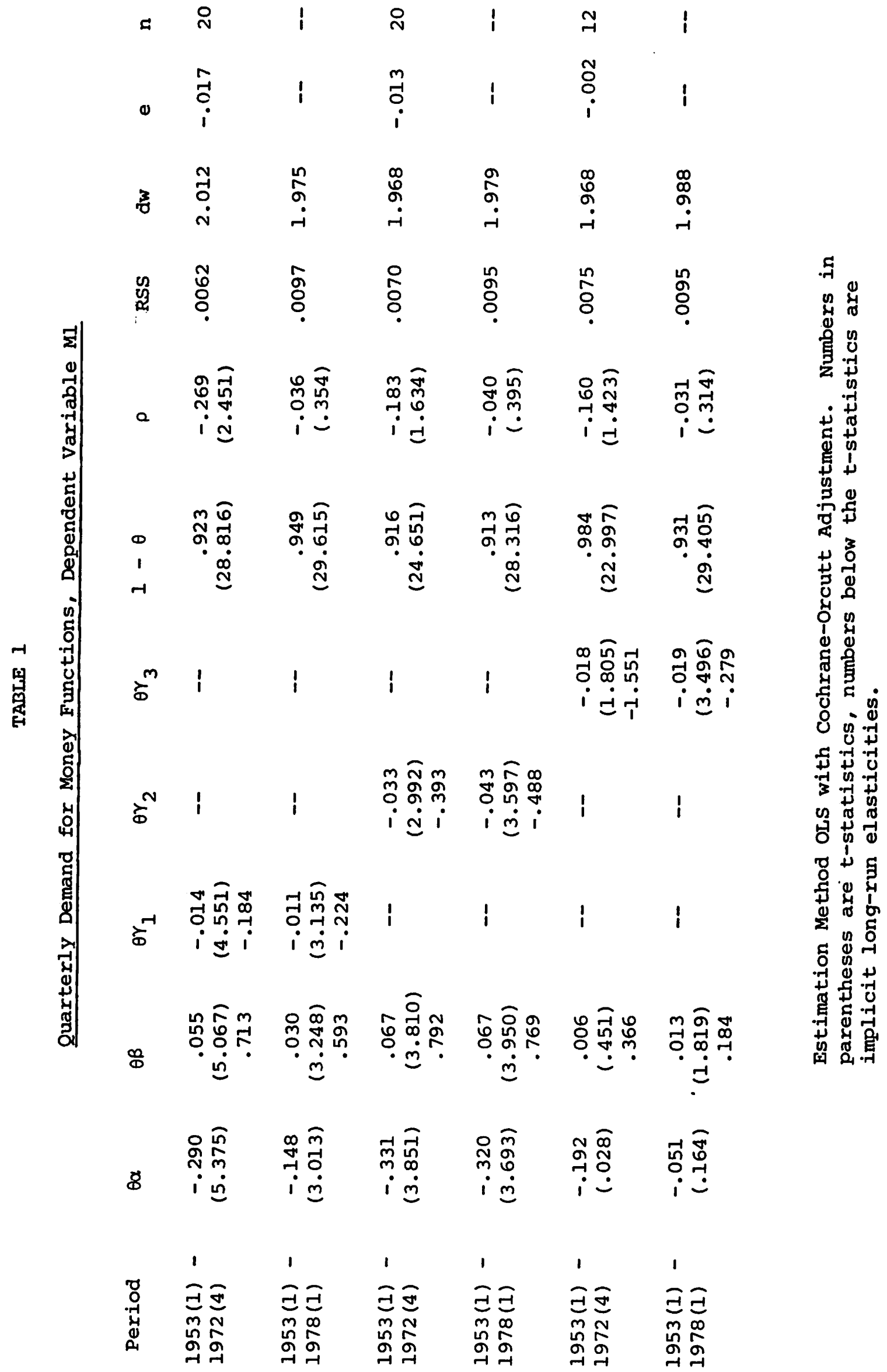




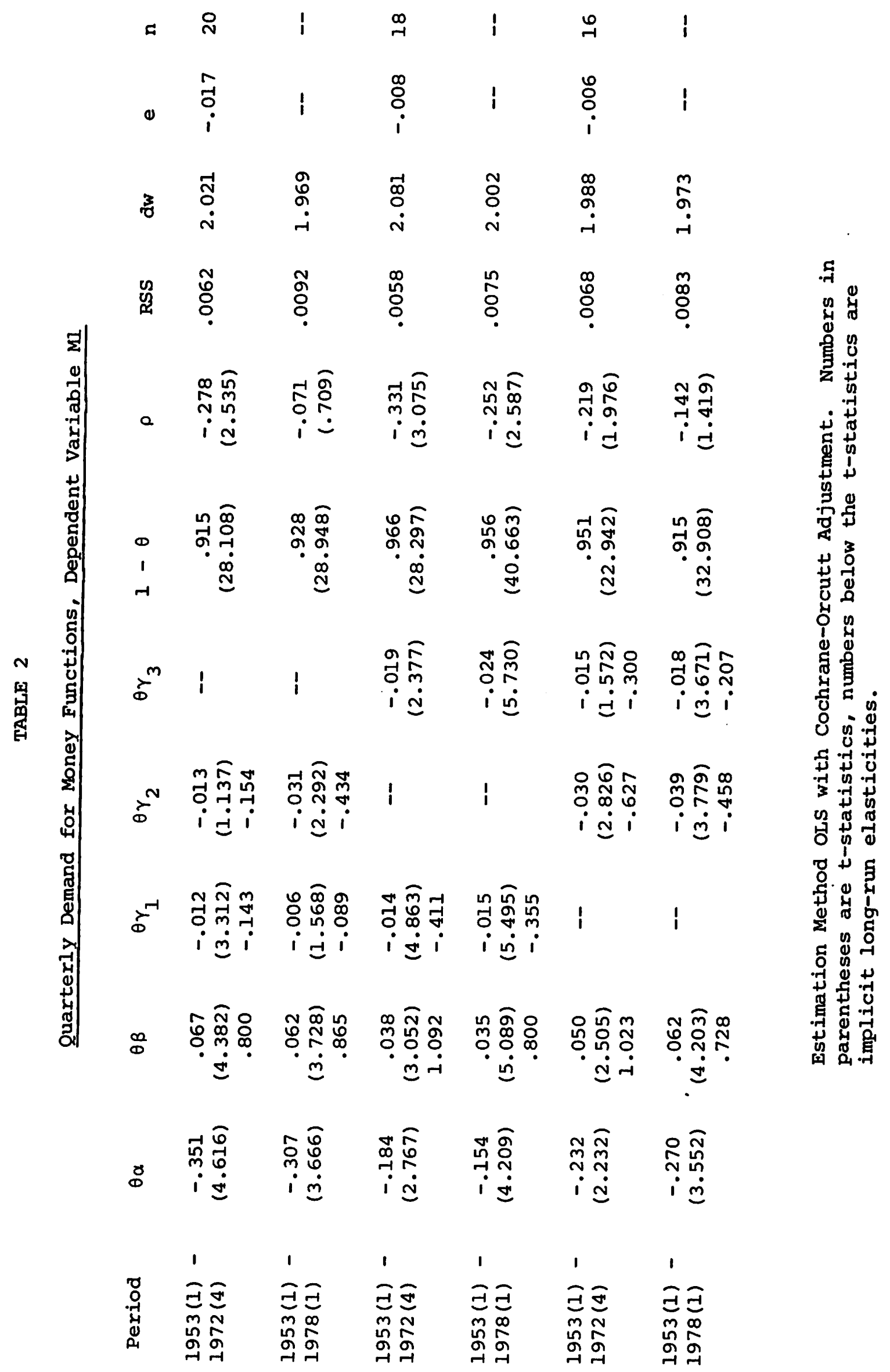




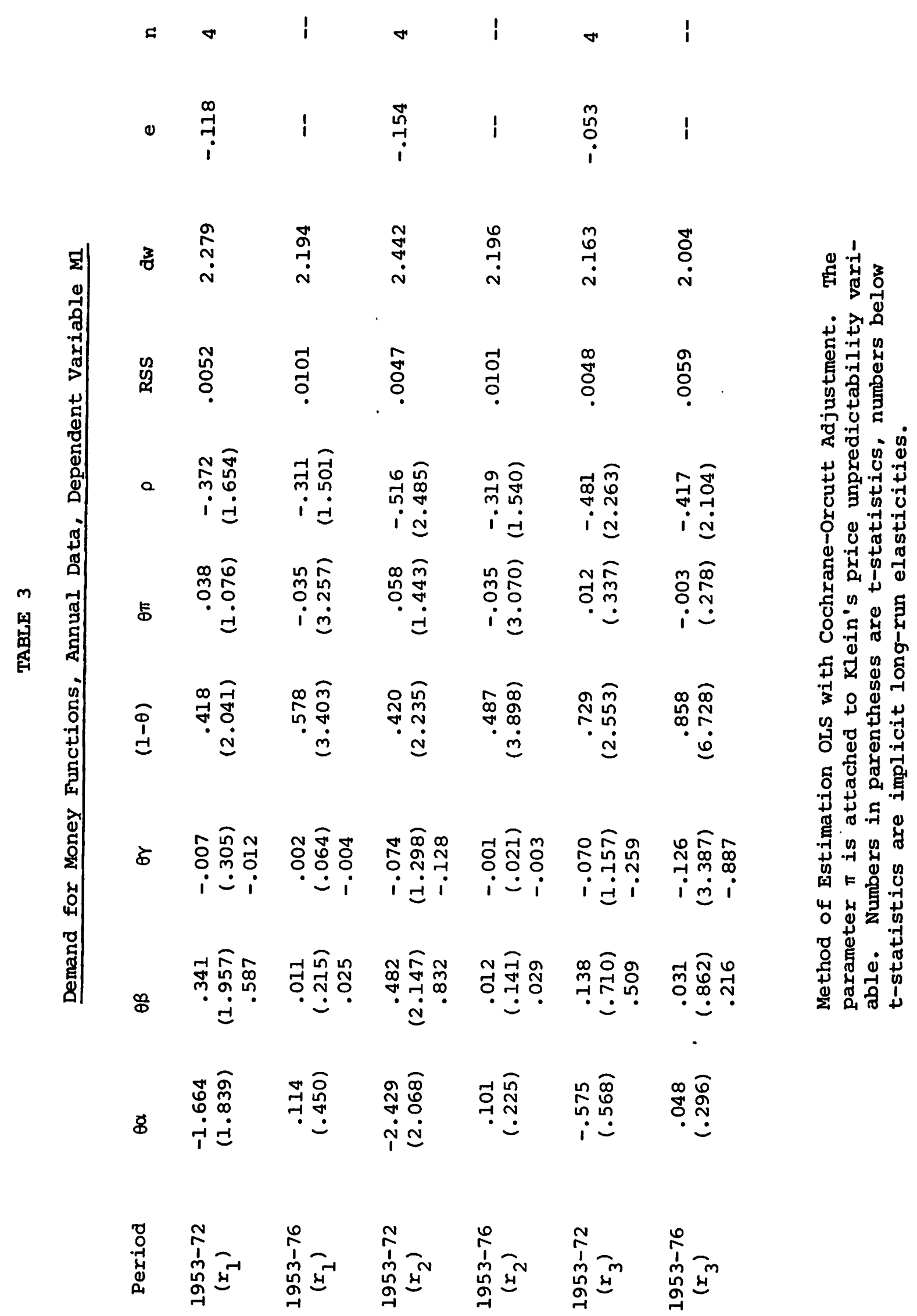




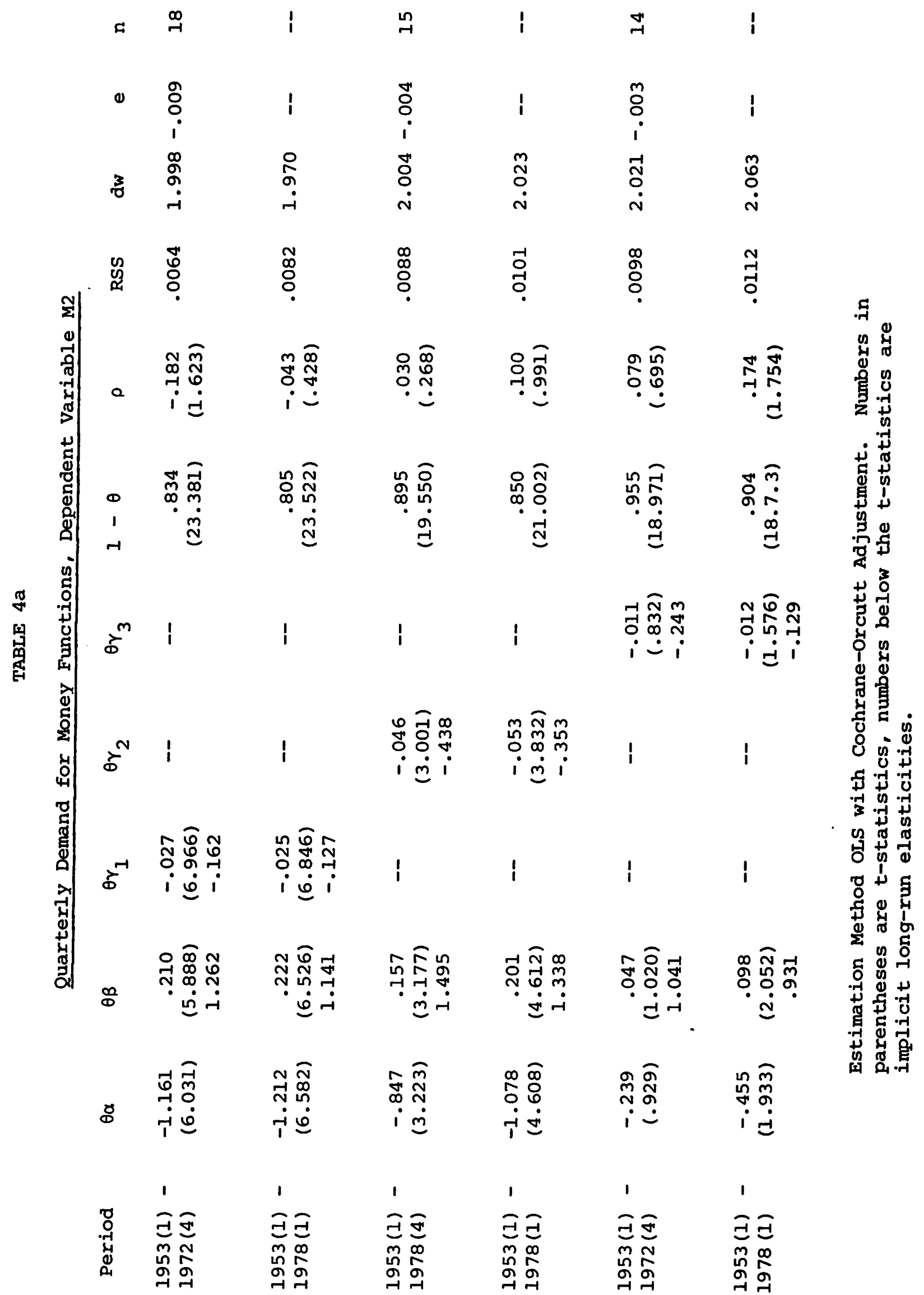




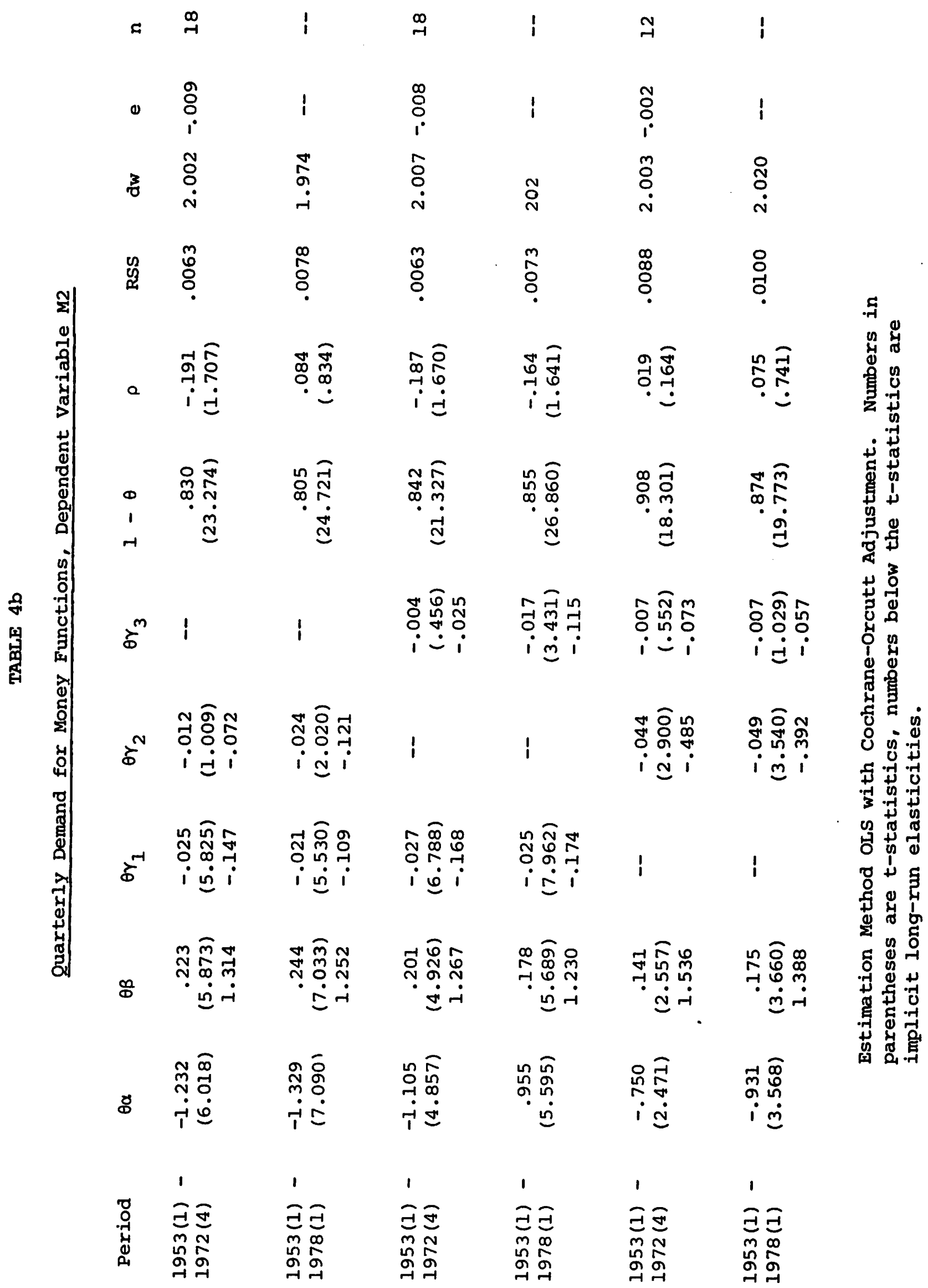




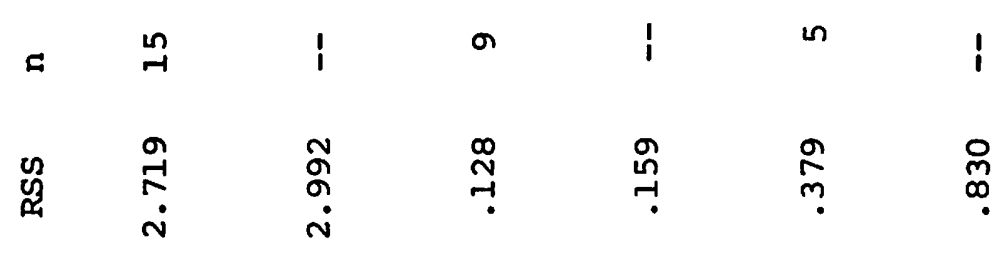

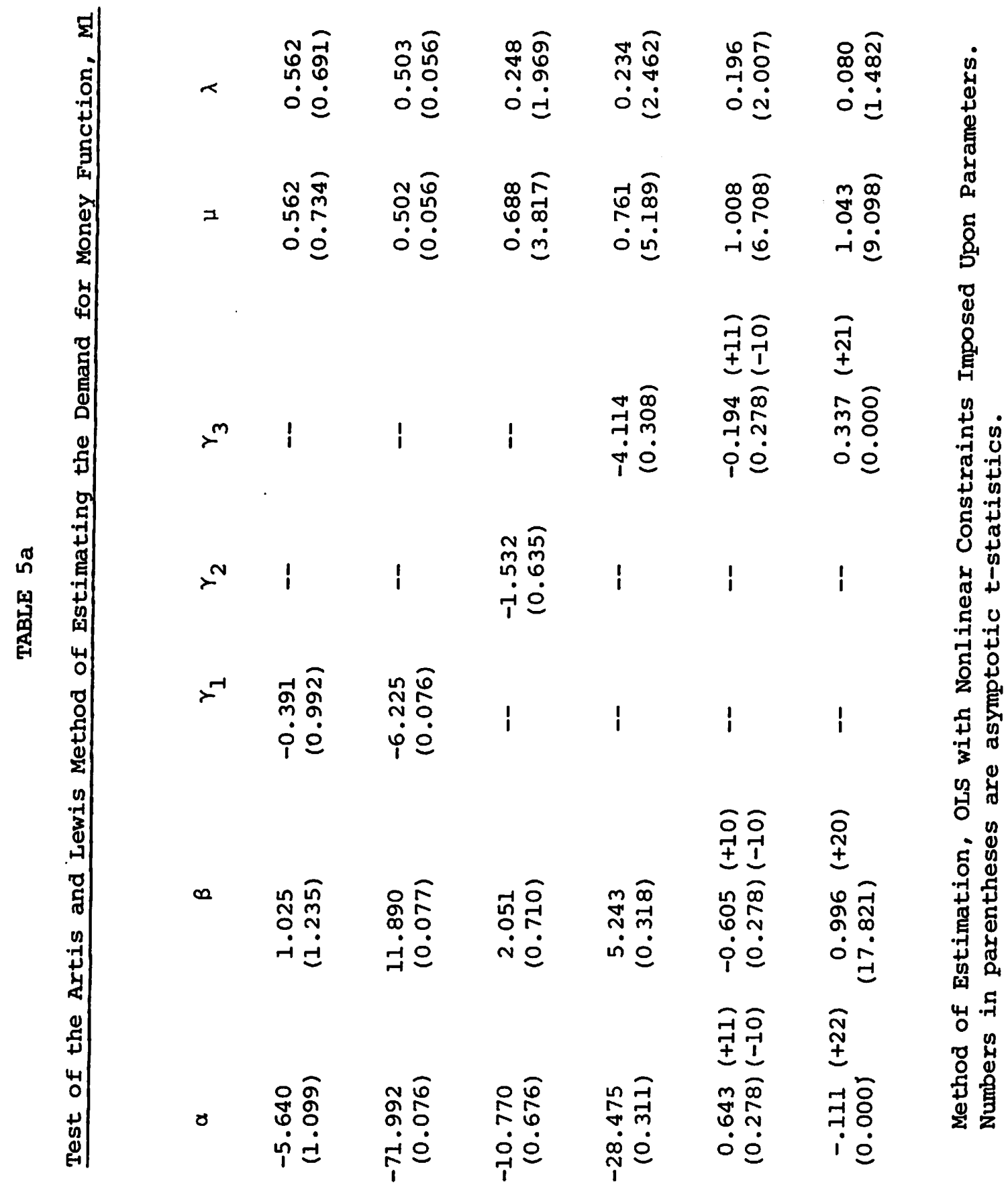

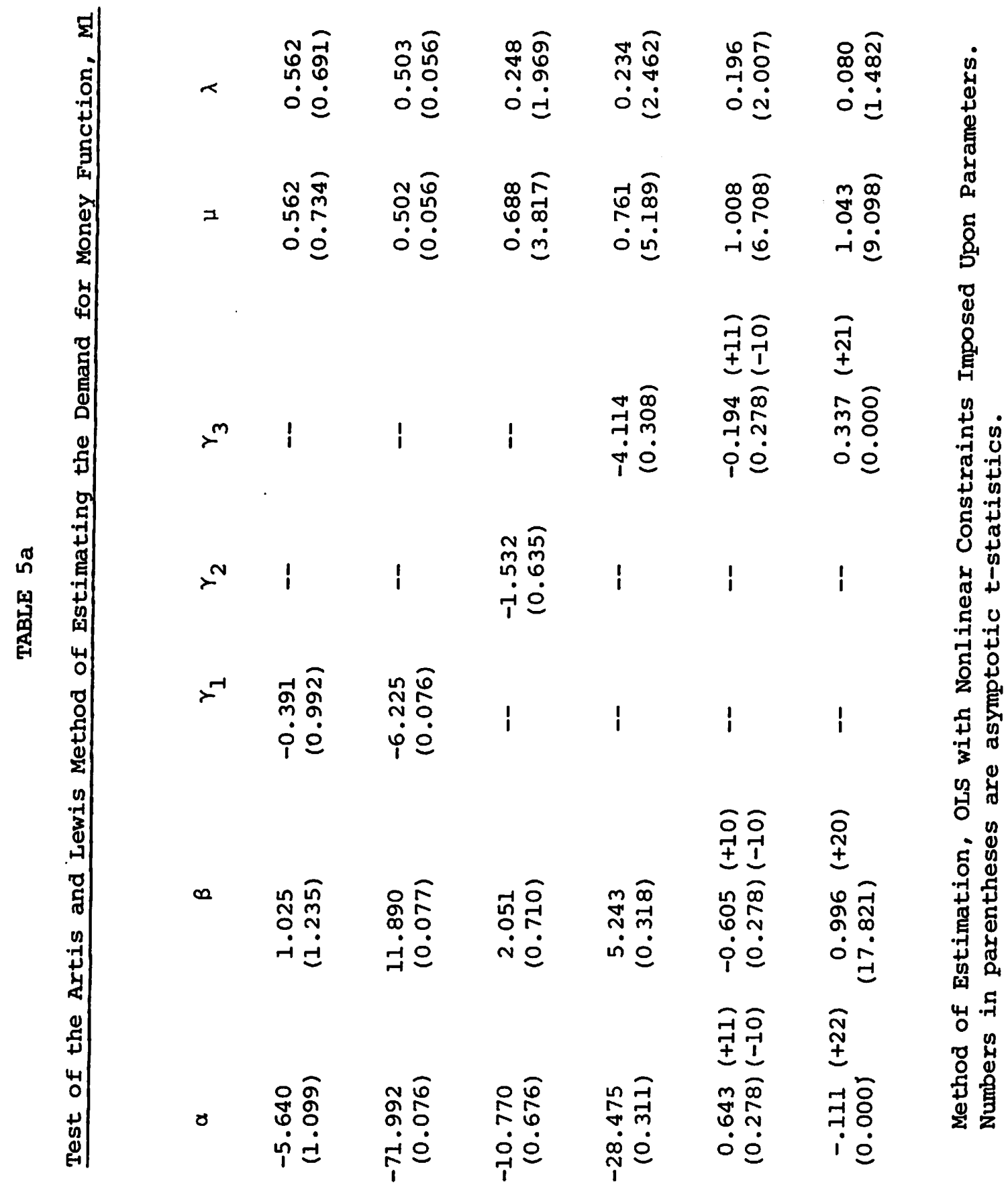

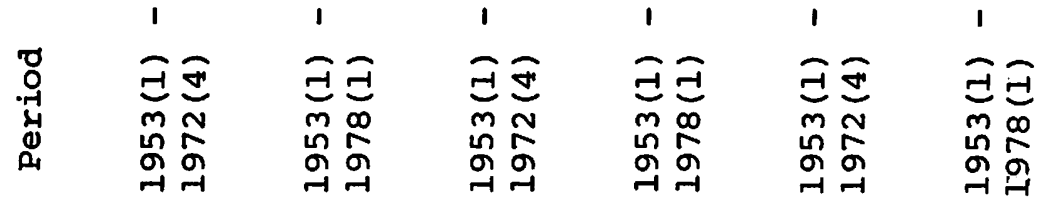




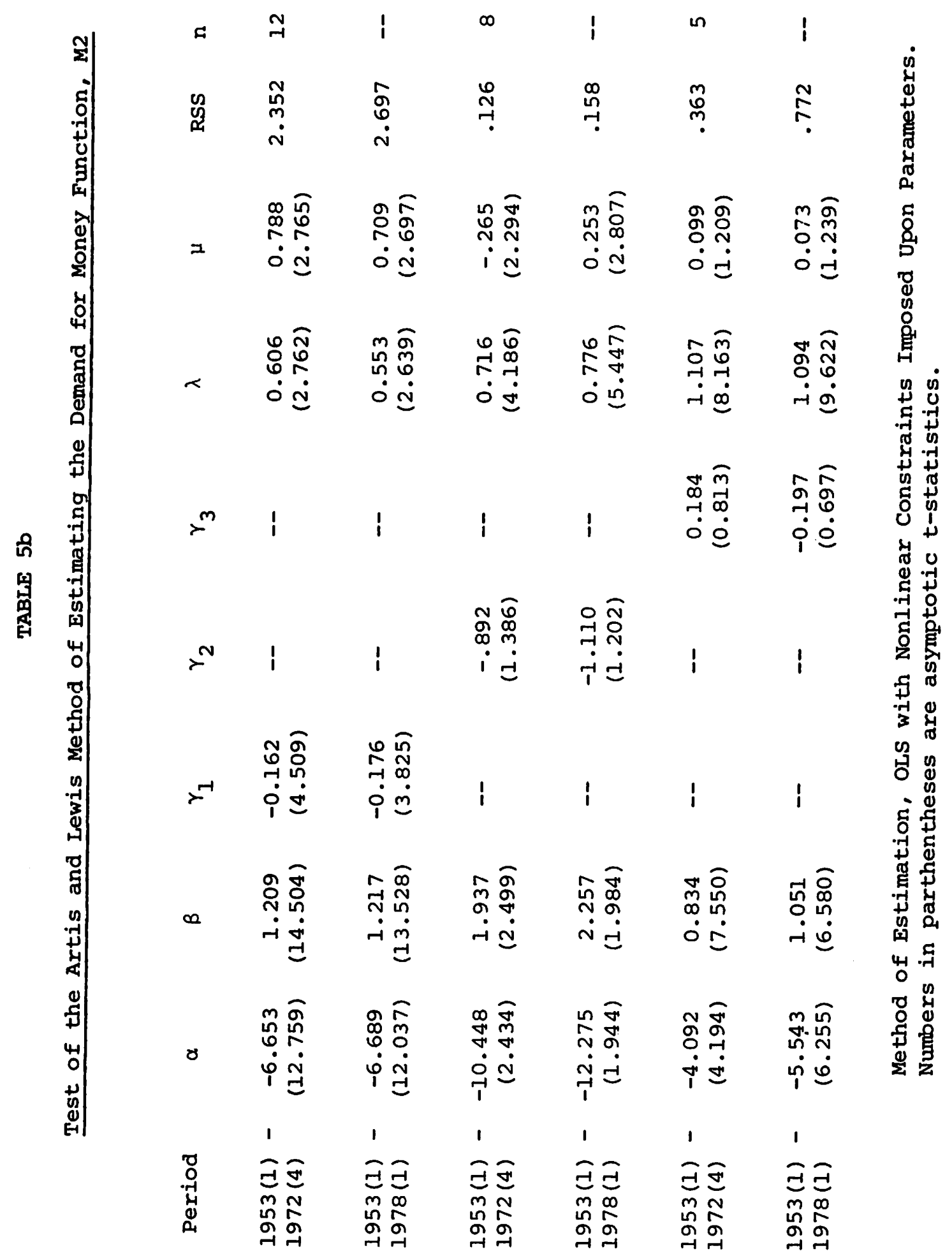




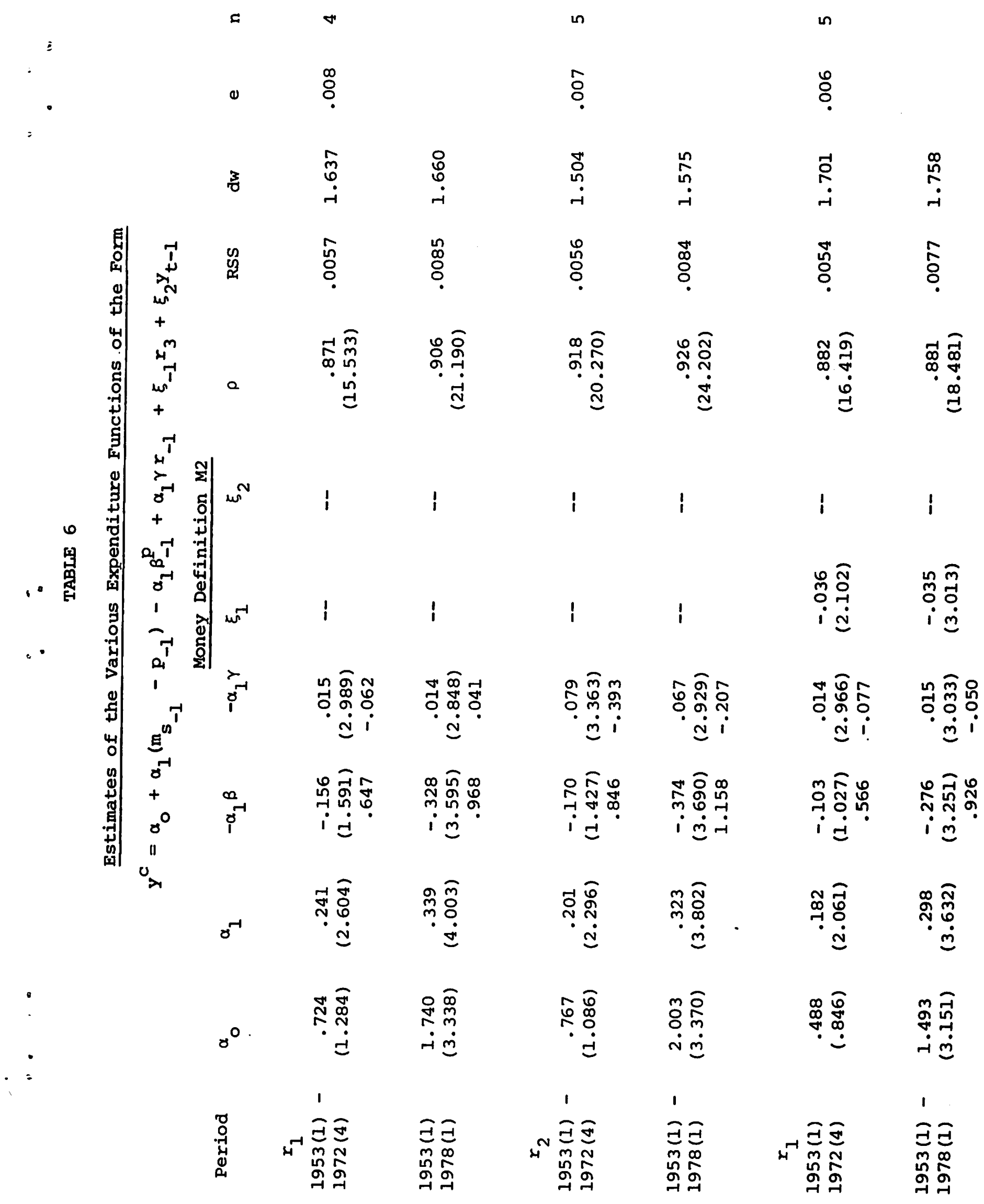




\begin{tabular}{|c|c|c|}
\hline G & in & $\stackrel{m}{r}$ \\
\hline (v) & $\stackrel{\circ}{\circ}$ & ষั \\
\hline
\end{tabular}

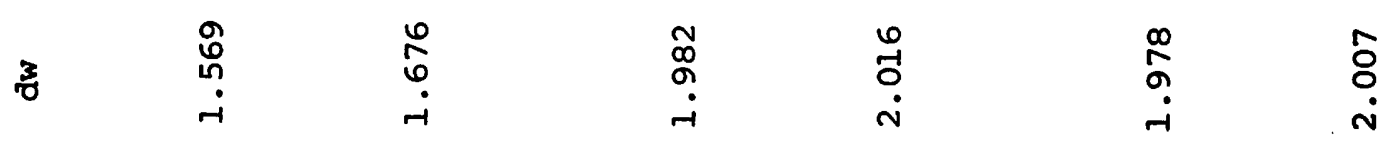

นิ กิ

$\begin{array}{ll}\mathbb{1} & \stackrel{0}{n} \\ 0 & 8\end{array}$

กิ

品.

ก̊̊

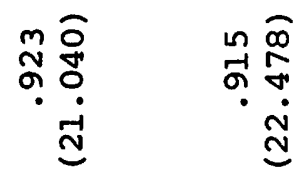

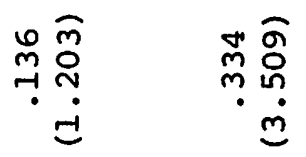

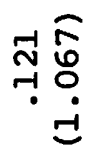

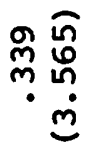

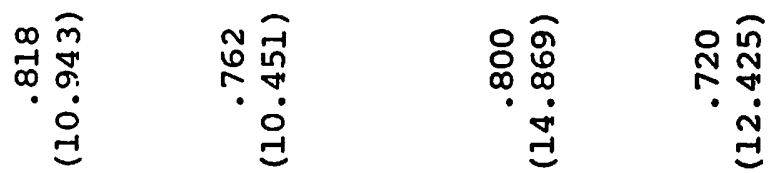

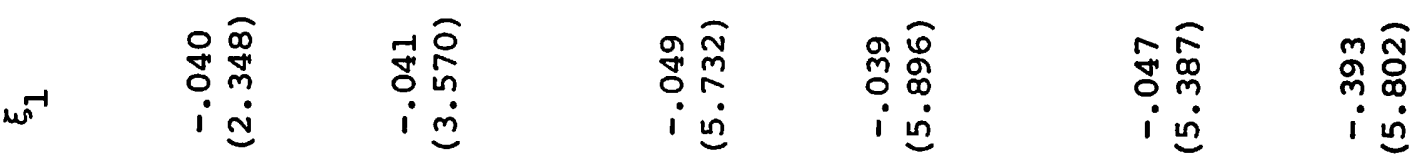

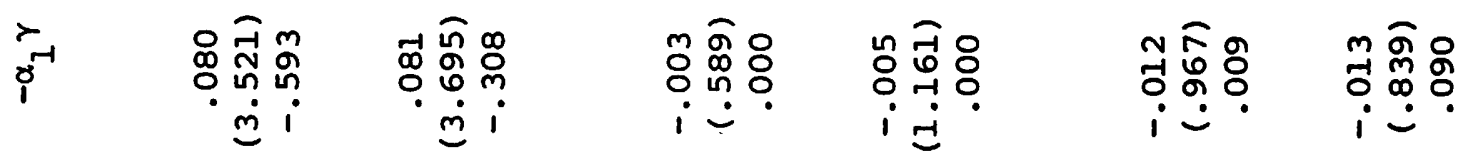

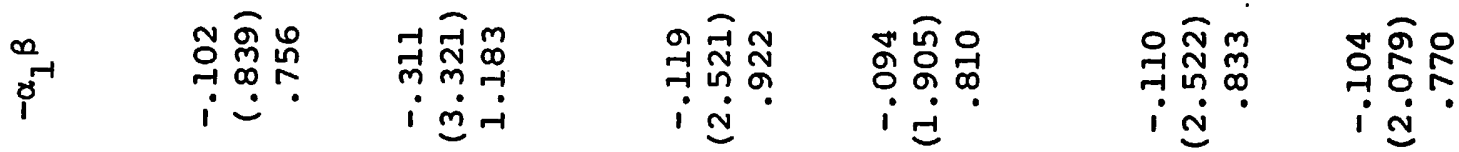

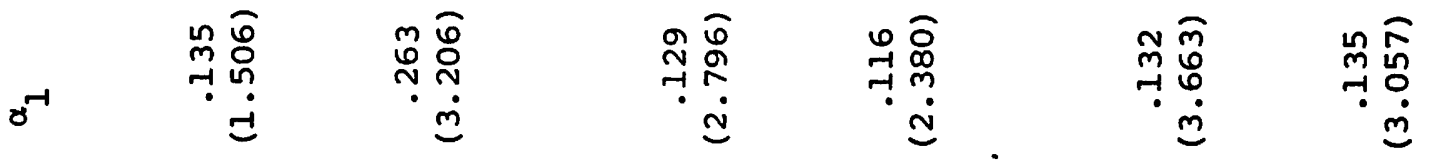

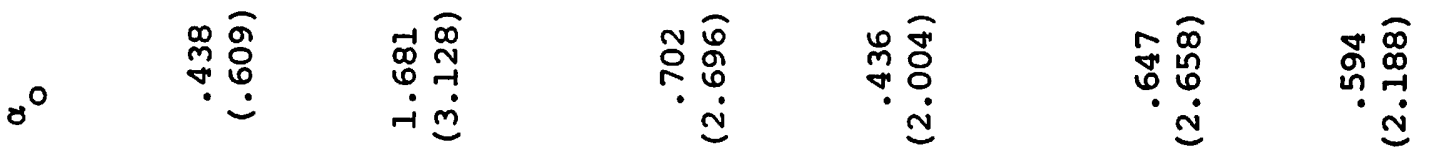

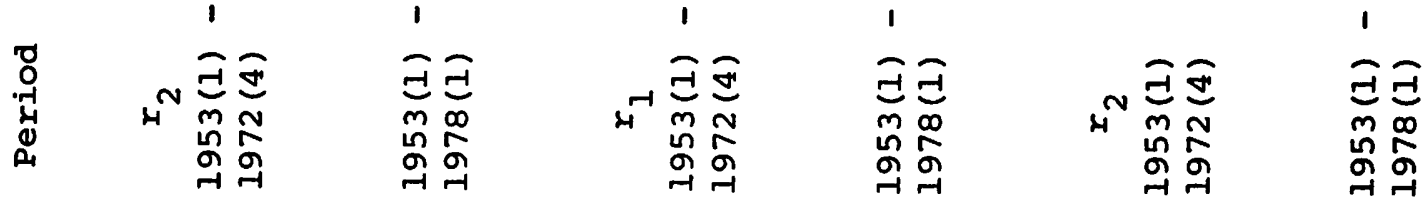


$\stackrel{7}{7}$
0
0

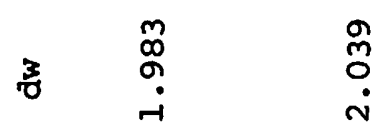

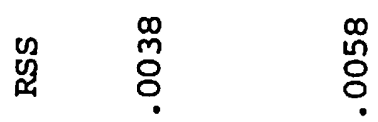

- 러

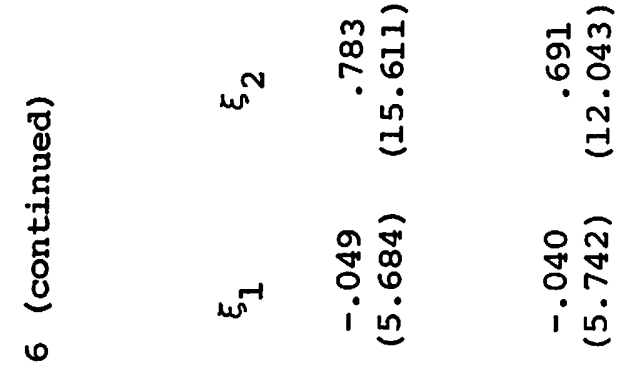

..

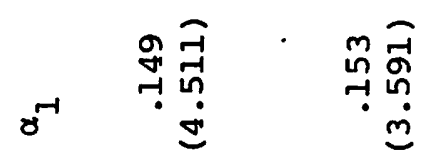

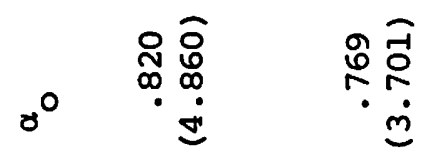

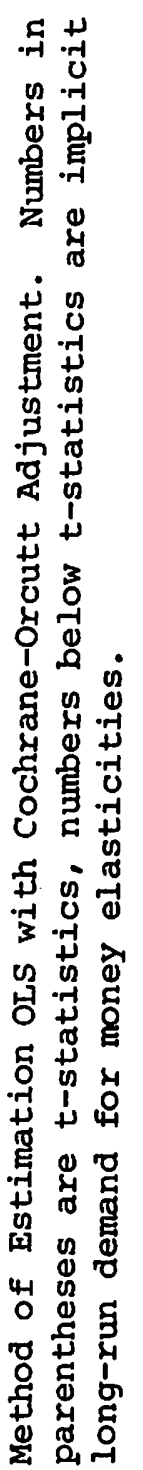

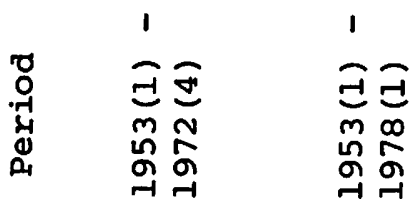




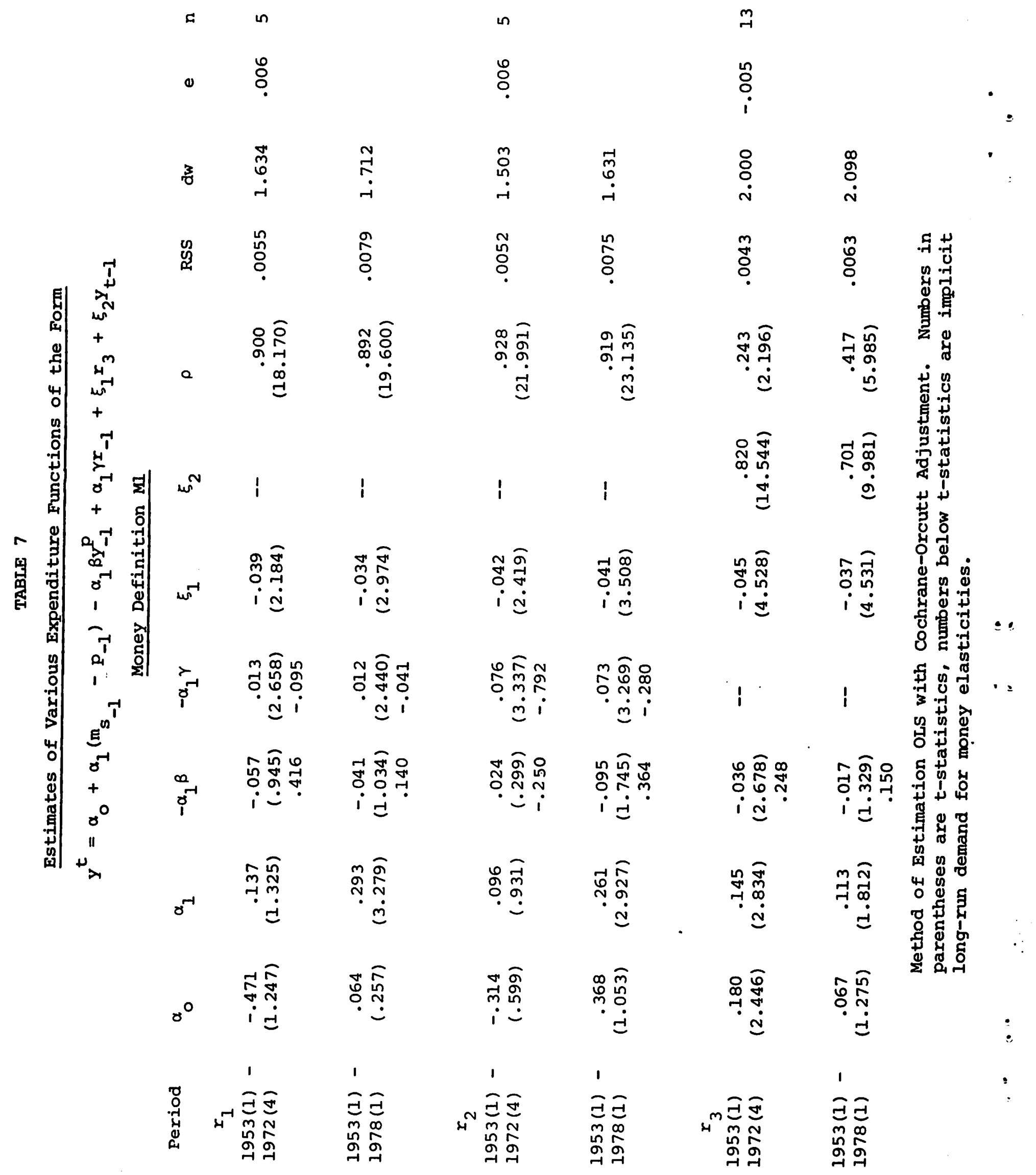




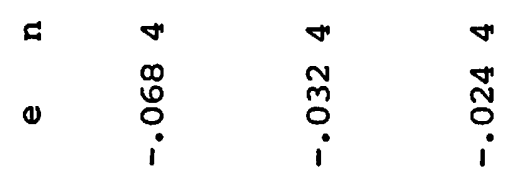

$\begin{array}{lll}\stackrel{0}{m} & \stackrel{0}{N} & \stackrel{N}{N} \\ & \stackrel{i}{N} & \stackrel{i}{N}\end{array}$

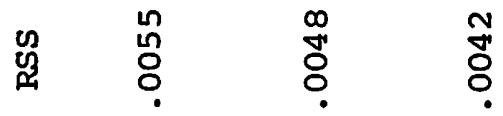

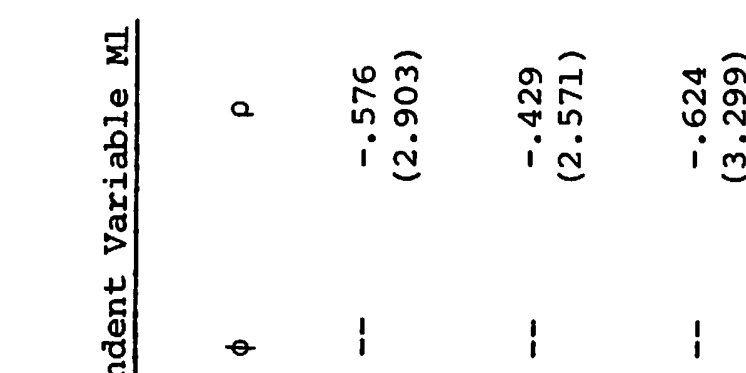

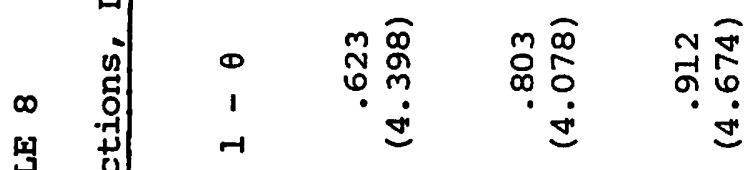

空

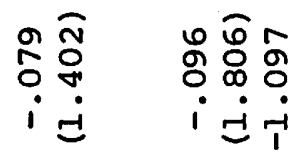

के 1 id $\quad$ i

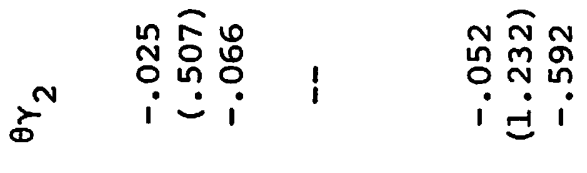

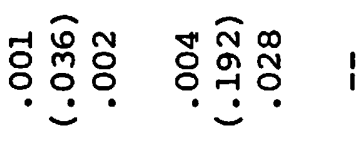

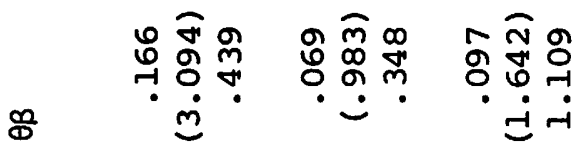

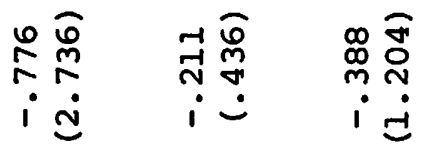

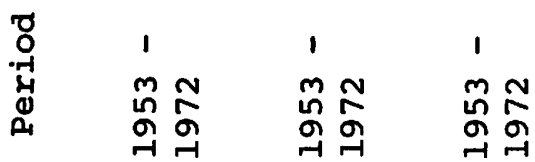




\begin{tabular}{|c|c|c|c|c|c|}
\hline I & $m$ & 1 & $m$ & 1 & $v$ \\
\hline (1) & $\begin{array}{l}\text { ले } \\
\text { i }\end{array}$ & i & $\begin{array}{l}\stackrel{\infty}{N} \\
\stackrel{0}{i}\end{array}$ & i & $\begin{array}{l}N \\
0 \\
0\end{array}$ \\
\hline
\end{tabular}

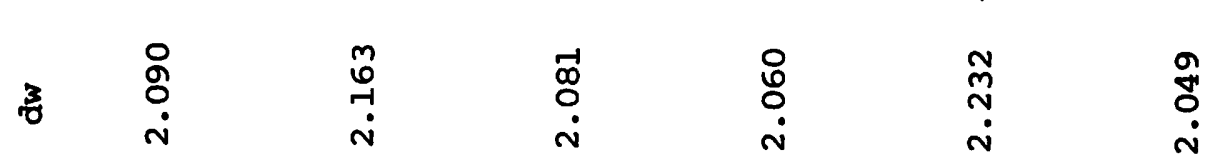

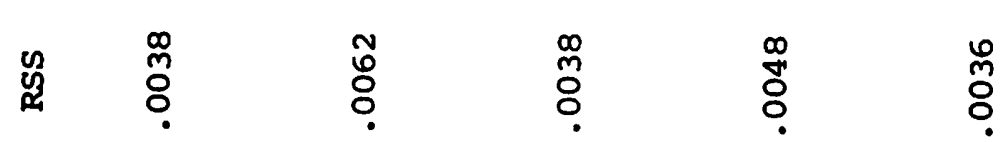

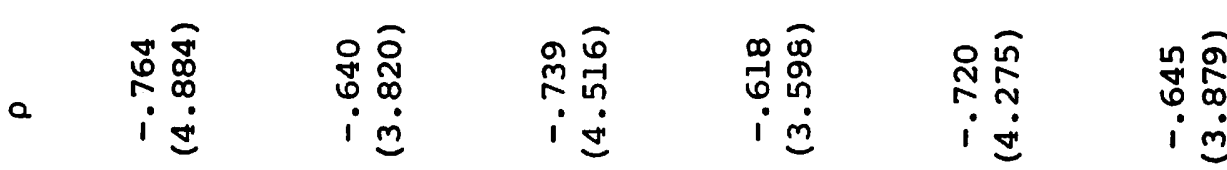

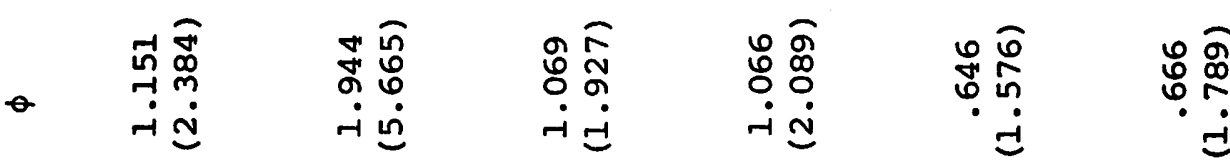

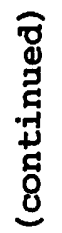

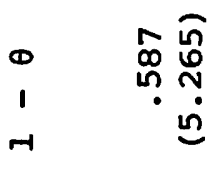

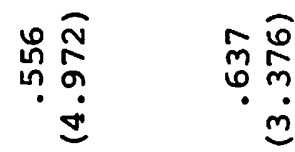

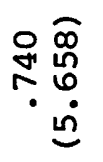

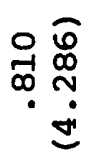

พั

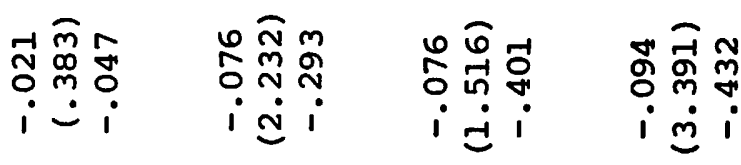

D.

奥

$\overleftarrow{\sigma}^{m} \quad$ ।

i

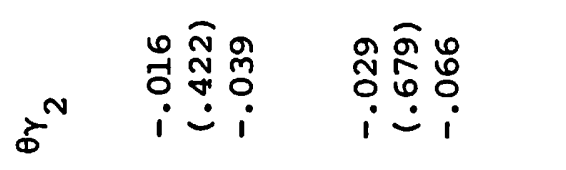

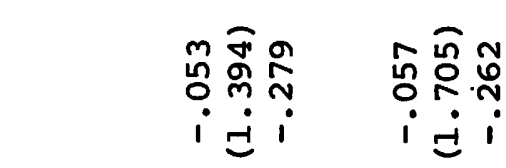

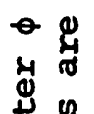

४ द्व

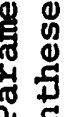

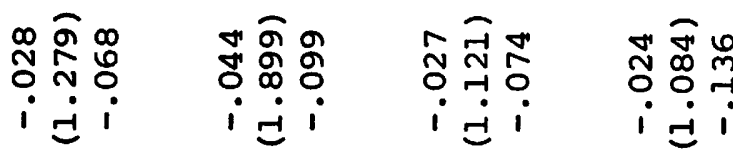

है $^{-1}$

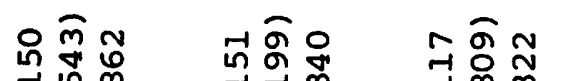

กิำ

$\stackrel{\infty}{\infty} \stackrel{m}{m}_{\infty}^{\infty}$

.

$\stackrel{\infty}{-}$

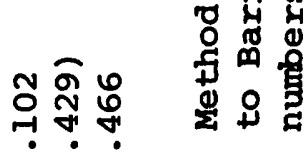

๓̊

in

लृ

-i

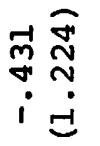

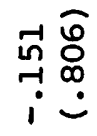

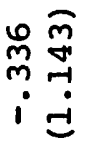

$\infty$
o
i
i

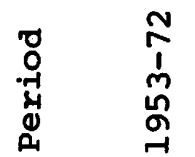

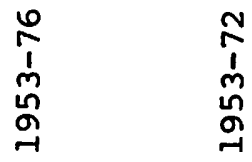

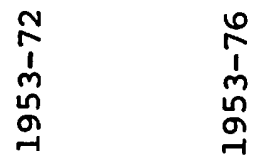

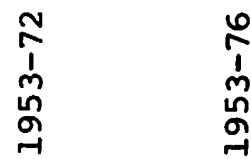




\section{BIBLIOGRAPHY}

Artis, M. J. and M. K. Lewis (1976), "The Demand for Money in the United Kingdom, 1963-1973," Manchester School 44, June, 147-181.

Barro, R. J. (1977), "Unanticipated Money Growth and Unemployment in the United States," American Economic·Review 67, March, 101-115.

Barro, R. J. (1978), "Unanticipated Money, Output and the Price Level in the United States," Journal of Political Economy 86, August, 549-580.

Barro, R. J. and S. Fischer (1976), "Recent Developments in Monetary Theory," Journal of Monetary Economics 2, May, 133-168.

Barro, R. J. and A. M. Santomero (1972), "Household Money Holdings and the Demand Deposit Rate," Journal of Money, Credit and Banking 4, May, $397-413$.

Barro, R. J. and A. M. Santomero (1974), "Transactions Costs, Payment Periods, and Employment," in H. G. Johnson and A. R. Nobay (eds.), Issues in Monetary Economics, London, Oxford University Press.

Baumol, W. J. (1952), "The Transactions Demand for Cash: An Inventory Theoretic Approach," Quarterly Journal of Economics 66, November, 545-556.

Bergstrom, A. R. and C. R. Wymer (1974), "A Model of Disequilibrium Neoclassical Growth and Its Application to the United Kingdom," London School of Economics International Monetary Research Programme mimeo. Boughton, J. M. (1979), "Demand for Money in Major OECD Countries," OECD EConomic Outlook Occasional Studies, January, 35-57.

Brunner, K. and A. H. Metlzer (1964), "Some Further Evidence on Supply and Demand Functions for Money," Journal of Finance 19, May, 240-283.

Brunner, K. and A. H. Meltzer (1972), "Money Debt and Economic Activity," . Journal of Political Economy 80, September/October, 951-977. 
Brunner, K. and A. H. Meltzer (1976), "An Aggregative Theory for a Closed Economy," in J. I. Stein (ed.), Monetarism, Amsterdam, Morth-Holland.

Cagan, P. (1956), "The Monetary Dynamics of Hyperinflation," in M. Friedman (ed.), Studies in the Quantity Theory of Money, Chicago, University of Chicago Press.

Cagan, P. and A. J. Schwartz (1975), "Has the Growth of Money Substitutes Hindered Monetary Policy?" Journal of Money, Credit and Banking 7, May, $137-160$.

Carlson, J. A. and J. R. Frew (1978), "The Demand for Money, Some Interest Elasticity Issues," Purdue University mimeo.

Carr, J. and M. R. Darby (1978), "The Role of Money Supply Shocks in the ShortRun Demand for Money," UCLA Department of Economics Discussion Paper \#98.

Chow, G. (1966), "On the Long-Run and Short-Run Demand for Money," Journal of Political Economy 74, April, 111-131.

Darby, M. R. (1972), "The Allocation of Transitory Income Among Consumers' Assets," American Economic Review 62, December, 928-941.

Enzler, J., L. Johnson and J. Paulus (1976), "Some Problems of Money Demand," Brookings Papers on Economics Activity, 261-280.

Feige, E. L. (1964), The Demand for Liquid Assets: A Temporal Cross-Section Analysis, Englewood Cliffs, NJ, Prentice-Hall.

Feige, E. I. (1967), "Expectations and Adjustments in the Monetary Sector," American Economic Review 57, May, 462-473.

Feige, E. L. and J. M. Parkin (1971), "The Optimal Quantity of Money, Bonds, Commodity Inventories and Capital," American Economic Review 61, June, 335-349.

Feige, E. L. and D. K. Pearce (1976), "The Substitutability of Money and Near Monies: Survey of the Time Series Evidence," Journal of Economic Literature 15, June, 439-469. 
Frenkel, J. (1977), "The Forward Exchange Rate, Expectations and the Demand for Money: The German Hyperinflation," American Economic Review 67, September, 653-670.

Friedman, B. M. (1978), "Crowding Out or Crowding In? Economic Consequences of Financing Government Deficits," Brookings Papers on Economic Activity 3, 593-64l.

Friedman, M. (1959), "The Demand for Money: Some Theoretical and Empirical Results," Journal of Political Economy 67, June, 327-351.

Friedman, M. (1977), "Time Perspective in Demand for Money," University of Chicago mimeo.

Goldfeld, S. M. (1973), "The Demand for Money Revisited," Brookings Papers on Economic Activity 3, 577-638.

Goldfeld, S. M. (1976), "The Case of the Missing Money," Brookings Papers on Economic Activity 3, 683-739.

Hacche, G. (1974), "The Demand for Money in the United Kingdom; Experience Since 1971," Bank of England Quarterly Bulletin, September.

Hamburger, M. J. (1977), "The Behavior of the Money Stock: Is There a Puzzle," Journal of Monetary Economics 3, July, 265-288.

Hamburger, M. J. and G. E. Wood (1978), "Interest Rates and Monetary Policy in Open Economies," mimeo.

Heller, H. R. and M. S. Khan (1979), "The Demand for Money and the Term Structure of Interest Rates," Journal of Political Economy 87, February, 109-129.

Howitt, P. W. and D. Laidler (1979), "Recent Canadian Monetary Policy: A Critique," University of Western Ontario mimeo.

Tbrahim, I. B. and R. Williams (1978), "Price Unpredictability and Monetary Standards: A Comment on Klein's Measure of Price Uncertainty," Economic Inguiry 16, July, 431-437. 
Jonson, P. D. (1976a), "Money and Economic Activity in the Open Economy: The United Kingdom 1880-1970," Journal of Political Economy 84, September/ October, 979-1012.

Jonson, P. D. (1976b), "Money Prices and Output: An Integrative Essay," Kredit und Kapital 4, 499-518.

Jonson, P. D., E. R. Moses and C. R. Wymer (1976), "A Minimal Model of the Australian Economy," Reserve Bank of Australia Discussion Paper 7601, Syaney.

Kaldor, N. (1970), "The New Monetarism," Lloyds Bank Review, July, 1-18.

Khan, M. S. (1979), "The Search for the Missing Money: Some New Evidence," IMF mimeo.

Khoury, M. and J. Myhrman (1976), "Econometric Analysis of the Demand for Money in Sweden, 1909-1968," University of Stockholm mimeo.

Klein, B. (1974), "Competitive Interest Payments on Bank Deposits and the LongRun Demand for Money," American Economic Review 64, December, 931-949.

Klein, B. (1977), "The Demand for Money and Quality Adjusted Cash Balances: Price Uncertainty in the US Demand for Money Function," Journal of Political Economy 85, August, 691-716.

Klein, B. (1978), "The Measurement of Long and Short-Term Price Uncertainty: A Moving Regression Time Series Analysis," Economic Inquiry 16, July, 438-453.

Knight, M. D. and C. R. Wymer (1978), "A Macroeconomic Model of the United Kingdom," IMF Staff Papers 25, 742-778.

Laidler, D. (1966), "Some Evidence on the Demand for Money," Journal of Political Economy 74, February, 55-68.

Laidler, D. (1969), "The Definition of Money: Theoretical and Empirical Problems," ", Journal of Money, Credit and Banking 1, August, 508-525. 
Laidler, D. (1975), Essays on Money and Inflation, Manchester, Manchester University Press, Chicago, University of Chicago Press.

Laidler, D. (1977), The Demand for Money: Theories and Evidence (2nd edition), New York, T. Y. Crowell.

Laidler, D. and P. O'Shea (1978), "An Empirical Macro Model of an Open Economy Under Fixed Exchange Rates: The United Kingdom 1954-1970," University of Western Ontario Research Report \#7810, mimeo.

Lewis, M. (1978), "Interest Rates and Monetary Velocity in Australia and the United States," Economic Record, April, 111-126.

Marty, A. (1961), "Gurley and Shaw on Money in a Theory of Finance," Journal of Political Economy 69, February, 56-62.

Meltzer, A. H. (1959), "The Behavior of the French Money Supply 1938-1954," Journal of Political Economy 67, June, 275-296.

Meltzer, A. H. (1963), "The Demand for Money: The Evidence from the Time Series," Journal of Political Economy 71, June, 219-246.

Meyer, P. A. and J. A. Neri (1975), "A Keynes-Friedman Money Demand Function," American Economic Review 65, September, 610-623.

Modigliani, F. (1977), "The Monetarist Controversy or Should we Forsake Stabilizațion Policies," American Economic Review 67, March, 1-19.

Norton, W. E. (ed.) (1978), Conference on Applied Economic Research, Reserve Bank of Australia, Sydney.

Perlman, M. (1971), "The Roles of Money in an Economy and the Optimum Quantity of Money," Economica NS 38, August, 233-252.

Spinelli, F. (1978), "The Demand for Money in Italy," University of Western Ontario, mimeo.

Spinelli, F. (1979), "A Model of the Italian Economy Under Fixed Exchange Rates," University of Western Ontario mimeo. 
Tobin, J. (1956), "The Interest Elasticity of Transactions Demand for Cash," Review of Economics and Statistics 38, August, 241-247.

Walters, A. A. (1965), "Professor Friedman on the Demand for Money," Journal of Political Economy 73, October, 545-551.

White, w. H. (1978), "Improving the Demand-for-Money Function in Moderate Inflation," IMF Staff Papers 25, 564-607. 